\title{
STATUS REPORT ON MIRROR ALTERNATIVES
}

W. C. Condit, T. K. Fowler, ard R. F. Post

February 3, 1976

Prepared for U.S. Energy Research \& Development

Administration under contract $: 10$. W-7405-Eng-48

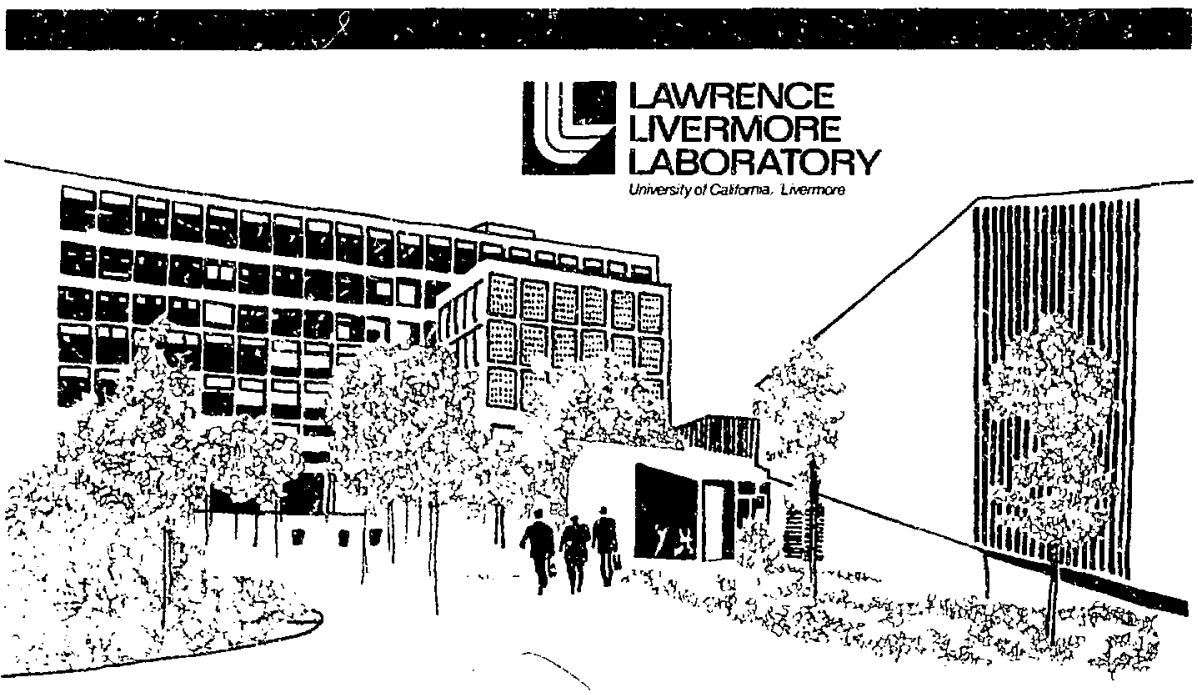




\section{NOTICE}

"This repost was prepated as an account of work sponsored by the United States Government. Neither the United States not the United Staies Energy Research 6 Development Administration, nor any of their employess, not any of their contractore. subcontractors, or their empluyces, makes iny warranty. express or implied, or assumes any iegal liability or responsibjlity for the securacy. completeness or usefulness of any information, apparatus, product or process disclosed, or represents that its use would not infringe privately-owned ights."

Printed in the United States of America Available from

National Technical Information Servire

U.S. Department of Commerce 5285 Port Royal Road Springfield, Virginia 22151

Price: Printed Copy $\$$; Microfiche $\$ 2.25$

$$
\begin{aligned}
& { }^{*} \text { Pages } \\
& 1-50 \\
& 51-150 \\
& 151-325 \\
& 326-500 \\
& 501-1000
\end{aligned}
$$

NTIS

Selling Price

$\$ 4.00$

$\$ 5.45$

$\$ 7.60$

$\$ 10.60$

$\$ 13.60$ 


\section{近 \\ LAWRENCE LNERMORE LABORATOPY University of Catiomia Livermore Celtornia 94550}

\section{UCRL-52008 \\ STATUS REPORT ON MIRROR ALTERNATIVES}

W. C. C.ndit, T. K. Fowler and R. F, Post

MS. Jate: February 3, 1976
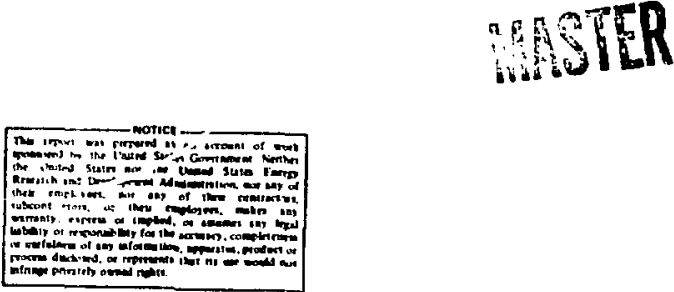


\section{Acknowledgments}

The work described here represents che effort and ideas of many people. A partial list follows:
0. A. Anderson
D. E. Baldwin
J. A. Byers
f. II, Coensgen
L. S. HaII
C. W. Ha.tman
B. G. logan
B. McNamara
R. W. Soir (and coauchors of Ref, 10)
k. A. Newcomb
D. S. Prono
N. E. Rensink
T. Rognlein
J. W. Shearer
J. R. Hiskes 


\section{Contents}

Abstrace . . . . . . . . . . . . . . . . . . . . . . . . . 1

1. Int roduction . . . . . . . . . . . . . . . . . . . . . 1

2. Studles in progress . . . . . . . . . . . . . . . . . . . . 2

3. Neans to lmprove i) . . . . . . . . . . . . . . . . . . . . . . 4 4

4. Field keversill . . . . . . . . . . . . . . . . . . . . . 5

Conigurat ional Slabllity . . . . . . . . . . . . . . . . . 6

Creating Fleld keversal by keutral lnjection . . . . . . . . . . . 7

5. Field opt ingation and simple Mirrors . . . . . . . . . . . . . . B

๖. Nirgortorus Hybrids . . . . . . . . . . . . . . . . . . . . . 9

7. Jong l.1near sachlnes. . . . . . . . . . . . . . . . . . . 10

H. sumbry. . . . . . . . . . . . . . . . . . . . . . . . . 10

Appendix A: Cosparison of Experinental and theoretical Limits on Beta. . js Appendix b: Q-Enhincement by Programmed Neutral Injectlon . . . . . . . 15

Appendix c: Analysis of the kurchat ov keversed-Field Experiment . . . . . 18

dppendix D: Heactor Potential of Reversed-field Mirror Configuration . 21

Appendx E: Conditions to ichieve Field keversal by Neutral Injection . 28

Appendix t: Intense ton beams . . . . . . . . . . . . . . . . . . . . . 32

Appendix c: 2xc lagnet set .. . . . . . . . . . . . . . . . . . . 36

Appendix li: Operat Ing Nodes and Trade-Offs for Mirror-Torus Meactors . 40

Reierences... . . . . . . . . . . . . . . . . . 50 


\begin{abstract}
The present status of studies at Lawrence I.tvermore laboratory (I.l.l) directed toward exploring varlants on the basle magnetic mirror conflnement concept is described. These studtes have emphasized those ideas that could lead most directly to improvements in

the sclentific and economic viabllity of fuston reactors based on the mirror concept, withln the general context of the extensive body of spectalized physties and technologe that has been develuped in the rourse of the Mirror program.
\end{abstract}

\title{
1. Introduction
}

As outlined in $\operatorname{Ref}, 1$, the Lawrence Livermore Laboratory (L.I.L) Virror Program is primarily directed toward a steady-state fusion reactor based upon a superconducting $Y$ in-Yang magnet, neutral beam injection, and direct conversion. In addition, a portion of our theory and design efforts is afmed at exploring improvements in this system and also alternative concepts employing the mirror confinement principle.

In these explozatory studies, we have mainly considered those ideas that use the physics and technology already being developed in the program. Thus, some Ideas can be tested directly in the 2XIIB and Baseball II-T experiments and the proposed MX experiment. In other cases, we have in mind the possiblity of further modifications of $2 \mathrm{X}$ a year or two hence, and later perhaps a major experiment on the scale of $M X$ and using the same 160-ill beam power supply, cryogenic facilities, and controls

Thus, largely by ut $11 \mathrm{izing}$ facilities that would already exist in the malnline program, promising new mirror ideas could be pursued at a relatively small additional cost. In most cases, the largest new expenditure would be a new magnet set; for reference, the $M X$ magnet itself ts only $10 \%$ of the total cost of the MX facility. 


\section{Studies in Progress}

The following is a list of five categories of exploratory mirror ideas that have received the most attention in recent montis:

- Neans to Jmprove 0. Th:3 includes Fokker-Planck studles to optimiae infectlon parameters as well as additional machine components almed at improving the rat lo of fuston power to injected power, denoted by $Q$.

- Field reversal. This concerns the possibility that plasma currents in the mirror machine can be made to form a stable, closed pattern of magnetic lines, similar to the Astron or reversed-field, theta-pinch configurations.
- Field optimtation and simple mirrors. This concerns mirror field designs that might be simpler and less expensive than the Yin-Yang, while preserving magnetohydrodynam1c (MHD) stability.

- Nirror-torus hybrids. This concerns toroldal peometries that also involve $\mathrm{ml}$ rror confluement in an essential way I for example: the Ion Bumpy Torus (1BT) :

- long lt near machines. This includes the two-component mirror concept, multiple-mirrors, and long solenotds.

The status and present evaluation of each of these study categories are out]ined in Table 1. Mure detalls appear in the sectlons that follow. 
Tahle 1. Summary and present evaluation of mirror alternatives studies

\begin{tabular}{|c|c|c|c|c|}
\hline Category & Problems & $\begin{array}{l}\text { Aval lable } \\
\text { theorettcal } \\
\text { tools }\end{array}$ & $\begin{array}{l}\text { Applicable } \\
\text { near-term } \\
\text { experimencs }\end{array}$ & $\begin{array}{l}\text { Present } \\
\text { evaluation }\end{array}$ \\
\hline $\begin{array}{l}\text { Neans to } \\
\text { improve ? }\end{array}$ & $\begin{array}{l}\text { Detniled } \\
\text { bilance of } \\
\text { pains and } \\
\text { losses }\end{array}$ & $\begin{array}{l}\text { Mainly Fokker- } \\
\text { Planck codes }\end{array}$ & $\begin{array}{l}\text { 1. } 2 \text { XIIB, Base- } \\
\text { ba } 11 \text { II-T, } \\
\text { (: } 1 \text { imits) }\end{array}$ & $\begin{array}{l}\text { Should continue } \\
\text { theoretical study: } \\
\text { might increase Q by } \\
\text { 50\% and decrease } \\
\text { mirror reactor cost } \\
\text { proportionately. }\end{array}$ \\
\hline $\begin{array}{l}\text { Field } \\
\text { reversial }\end{array}$ & $\begin{array}{l}\text { 1. MhD } \\
\text { stabtlity } \\
\therefore \text { Stirtup }\end{array}$ & $\begin{array}{l}\text { 1. SLPFRIAYER } \\
\text { code re- } \\
\text { vlsed for } \\
\text { neutral } \\
\text { injection } \\
\text { 2. Stabllity } \\
\text { analysis }\end{array}$ & $\begin{array}{l}\text { 1. Cornell } \\
\text { Astrun: } \\
\text { kurtmullate } \\
\text { experiment } \\
\text { 2. Posstbly } \\
\text { 2xisB } \\
\text { 3. High-inten- } \\
\text { sity ion } \\
\text { sources }\end{array}$ & $\begin{array}{l}\text { Should actively pur- } \\
\text { sue: tas greatest } \\
\text { potential for small, } \\
\text { cheap reactor, though } \\
\text { still great uncer- } \\
\text { tainty in physics. } \\
\text { Needs derelopment cf } \\
\text { intense ion sources. }\end{array}$ \\
\hline $\begin{array}{l}\text { Field } \\
\text { optimiza- } \\
\text { tion and } \\
\text { simple } \\
\text { mirror }\end{array}$ & $\begin{array}{l}\text { 1. शHD beta } \\
\text { limit } \\
\text { 2. Heat loss } \\
\text { by "line } \\
\text { tying" }\end{array}$ & $\begin{array}{l}\text { 1. 3D equili- } \\
\text { brium code } \\
\text { 2. Stability } \\
\text { analysis }\end{array}$ & $\begin{array}{l}2 X C \text { and cer- } \\
\text { tain aspects } \\
\text { of } 2 X I I B\end{array}$ & $\begin{array}{l}\text { Should build } 2 \mathrm{XC} \text { : } \\
\text { could substantially } \\
\text { reduce reactor cost } \\
\text { and magnet develop- } \\
\text { ment. }\end{array}$ \\
\hline $\begin{array}{l}\text { Nirror- } \\
\text { torus } \\
\text { hybrlds }\end{array}$ & $\begin{array}{l}\text { 1. MHD beta } \\
\text { limits } \\
\text { 2. lield } \\
\text { design }\end{array}$ & $\begin{array}{l}\text { 1. Field de- } \\
\text { sign codes } \\
\text { 2. Point modei } \\
\text { energy -bai- } \\
\text { ance code }\end{array}$ & $\begin{array}{l}\text { 1. } 2 \text { XC (to } \\
\text { model a } \\
\text { single } \\
\text { mirror cell) } \\
\text { 2. Elmo Bumpy } \\
\text { Torus (EBT) } \\
\text { 3. TORLAC, } \\
\text { MIRICLE }\end{array}$ & $\begin{array}{l}\text { Ion Bumpy Torus (IBT) } \\
\text { may be promising if } \\
\text { simple mirror cell } \\
\text { can be made to work. }\end{array}$ \\
\hline $\begin{array}{l}\text { Long } \\
\text { linear } \\
\text { machines }\end{array}$ & $\begin{array}{l}\text { i. large } \\
\text { size be- } \\
\text { cause of } \\
\text { heat } \\
\text { leakage } \\
\text { at the } \\
\text { ends }\end{array}$ & $\begin{array}{l}\text { 1. MARTENI } \\
\text { code } \\
\text { 2. Analytical } \\
\text { models }\end{array}$ & $\begin{array}{l}\text { 1. 2XIJB in } \\
\text { two-component } \\
\text { mode } \\
\text { 2. Mulciple- } \\
\text { mirror exper- } \\
\text { iments (UCB, } \\
\text { Novasibirsk) }\end{array}$ & $\begin{array}{l}\text { The size still seems } \\
\text { to be large. }\end{array}$ \\
\hline
\end{tabular}




\section{Means to Improve $Q$}

In our mirror reactor deslgns, $Q$ is calculated from the two-dimensional Fokker-Planci code with classical coefflcients. Previously, good agreement has been obtalied between classical Fokke:-Planck caiculat lcas and Baseball II dati with $l-$ to $2-k e V$ injection under fully stable cond 1 thons at low density." Bestues $Q$, the code now also calculates $B^{\circ}$ (In the "long, thin" plasma limit) and the axial density profile, all as functions of the mirror ratio, the beam energy, and the angle of injection relative to the midplane. optimum parameters are chosen to minimize the overall cost per kilowatt output. The main leverage on $Q$ in these calculations is the vacuum fleld mirror ratio, $R_{\text {vac }}$. However, assuming the peak mirror field to be fixed, the power output drops rapldly as $R_{v a c}$ increases. The optimum occurs around $Q=1$ for this model..$^{3}$ Increasing $Q$ from 1 to 2 with no change in $R_{\text {vac }}$ and $R$ would cut the plant cost almost in half for a given

* By including a charge-excinange term representing the measured gas density (comparable to scattering losses), the calculated and measured end losses 2 agreed within $5 \%$ for Baseball II runs with good varuum conditions (well within uncertain"y). power output and reduce the projected cost per kllowatt to around $\$ 1400 /$ $\mathrm{KW}_{\mathrm{e}}{ }^{3}$

It is entirely posstble that $Q$ is underestimated by out present cilleulational models, In the past, it had been assumed that high $B$ would decrease the scattering loss rate because the net mirror ratio would thereby be increased. As it has turned out, an essential feature of our present model by which these effects are calculated is that $Q$ is almust independent of $3 .{ }^{4}$ This is due to the fact that achieving high $B$ with the presently-used theory requires beam injection near enough to the loss-cone angle so that improvements in $Q$ are negated. However, the $2 \times I I B$ data has called thls model into question (see Appendix $A$ ). The model is based on ti:e foint conditions of stability to the MHD mirror mode and an equilibrium calculated in the limit of weak field curvature (the long, thin limit). In the $2 x I I B$ machine, the plasma $B=0.4$ or more, although the vacuum mirror ratio over the actual plasma length is less than 1.1. This disagrees with the results for the long, thin 1 imit and suggests the possibility that in the "short, fat" case the limit on $B$ with injection nearly 
perpendfcular to the magretic field may be significantly greater than that presently predicted. If so, the classical 0 value for a riven vacuum mirror ratio would be higher, accordingly.

Several other possibtlities for Improvements in (? are under study. Fur example. there is prellminary widance that a sprend in beam enerfices would help (thus far heams aro assumed mincenergetic). We bave also tritefly examined the pffects of augmented $r f$ heat ing at ion resonance $\left(k_{i j} \cdots 1\right)$. which ncts somewhat like rompressional "clanping" in the Toroldal Fusion Test Reactor (TFTR). Dawson and :orworkers have shown that tan cyclotron waves can raise $T_{\text {i }}$ and decrease $\left.T_{1}\right|^{5}$ A relatad idea not requiring $r$ equipment is a mode of operation in which the neutral beams are slowly pulsed on and of $f$, during which slow axtal expansion that decreases $T_{1}$, competes ith the increase in $r_{\mid}$by scattering. This possibtlity is discussed in Appendlx B. St ill another possibility, dis= cussed in section 6 , is the rectrculation of escaplang electrons through a toroldal loop in urder to improve the sertron hat conpinement (MIRICIf) .

While none of the above ideas has yet reached maturity, these ldeas indickte promising avenues to explore. Furthermore, other ideas will no loubt come along. Stuantile, the stability criteria in order that the classical results be valid are undergoing intensive reassessment, and diffusion coefficients to represent any residual turbulence are being incorporated in the Foikker-Planck code.

\section{Field Reversa!}

Two reversed-field configurations might be considered. One resembles Astron, in which a ring of very energetic fons encircling the axis would create the fleld configuration that confines the plasma. Since this configuration is one orbit in diameter, Ion energfes of many $\mathrm{MeV}$ are required in order to obtain a useful volume. This approach is now being pursued at Cornel1.
Iovelace has published a theory of the stability of this configuration.? Here, we shall discuss another possfbility, which we will call the reversed-field mirrot configuration, in whzch the plasma itself produces tield reversal. Created and sustained by neutral injection, it would simply be a different operating mode of the standard mirror machine, but one in which $Q$ would be expected 
to be enhanced by virtue of toroidal confinement. The configuration, shown in Fig. D-1, resembles a reversed-field theta $\mathrm{p} 1$ r.ch, or (since the plaisma seems to prefer a fatdoughnut shape) a diffuse, zoroidal, z-pinch with no stabilizing field. Thus, in this configuration, while one hopes for largely toroldal confinement, we would actually abandon the strong toroidal field that, while it helps to make a tokamak stable, at the same time constrains it to be a low-beta device.

\section{CONFIGURATIONAL, STABILITY}

At first sight, one would expect a reversed-ffeld configuration such as we describe to be unstable. A recent piece of experimental evidence has a bearing on this subject. ${ }^{8}$ Kurtaullaev and co-workers believe that they have created just such a state by first making a reversedfield theta pinch $\left(T_{i}=100 \mathrm{eV}\right)$ that then contiacts to a fat doughnut with reversed field and appears to persist stably for $50 \mathrm{~ms}$. They stress the importance of a strong multipole "barrier" field in their setup to prevent blowup during the contraction phase and a careful adjustment of parameters to insure that the final doughnut is fat enough to f 111 the tube.
Anderson and Newcomb at LLL have analyzed this experiment in some detail and find that it should have been unstable as judged by strict MHD theory (zero Larmor radius). They neglect the barrier field in their analysis.

Presuming that Kurtmullaev and h1s group have interpreted, leir experimental results correctly, we now belleve that the most probable explanation is fiute-orbit stabilization, together with an aspect ratio near unity (see Appendix $\mathrm{C}$ ). In essence, finite-orbit effects could provide internal rigidity if the aspect ratio also restricts az1muthal wavelengths to be a few times the minor diameter. An exception l.s the mocie of transverse displacement as a rigid body, which should be stabllized by minimum-B (the multipole fleld).

If a low aspect-ratio is essential, the configuration could only be achieved in a mirror machine or a solenold (e.g. a theta pinch). That is, the major axis must be free of obstructions (no ohmic heating, toroldal windings, etc) in order that the low aspect ratio can be attained. Finite orblt stabilization implies a restricted plasma volume, with a radius of only a few ton Larmor radil. The implications of this for plasma confinement and reactor economics are 
discussed briefly in Appendir: D. At first cut, it appears that the system could produce a few times $10 \mathrm{MW}$ per metre of le.igth at attractive capltal costs, and might be well sufted to modularized reactor construction.

CREATING FIEID REVERSAI BY NEUTRAL IN.ECTION

It: appears to be fundamental that, in a static fleld, fleld reversal can only be infiated by orbits encircling the axts, and this is borne out in our SUPERLAYER code runs. On the other hand, once the reversed-field con'iguration is achieved, further injection of lons with small orbits not encircling the axis could in principle produce diamagnetic currents maintaining the status quo. This suggests starting up such a system at low field so that all orbits encircle the axis initlally, and then programming the injection to maintain the reversed-field configuration as the field slowly increases to its steady-state value. We are now attempting to simulate this approach with the SUPERLAYER code.

Initial efforts to achiove field :eversal in 2XIIB with injection currents of over $300 \mathrm{~A}$ have not succeeded, despice favorable predictions by the code. In the code, we have found that injection symmetric to the axis does not produce reversal, whereas injecting orbits concentric to the axis does. However, in the experiment the maximum result was $B \approx 0.4$ in both cases. The reason appears to be a strong recurrence at high densiry of the same microinstability [drift cyclotron loss cone (DCLC) $?$ that dominates confinement in the absence of ti e stabilizing plasma sitiam needed at lower density.

Because of the difficulties thus far in trying to create reversed fields, we conslder the startup problem to be the criticalpath item. Learning from the Corne11 Astron experierce, we should therefore constder serlously the development of very rapid neutral injection in order to achleve the destred configuration before microinstabllities characteristlc of the nonreversed state can intervene.

A near-term solution to this problen might be a plasma gun. A gun capable of infecting $10^{18}$ particles at $10 \mathrm{kev}$ in a period of few microseconds has been described by Cheng. ${ }^{9}$

This gun would be adequate to produce fleld reversal in 2XIIB from a single unit. Neutralization of gun plasmas has been extensively studied at LLL, but these techniques have not yet ? n applied to cheng's gun design. Also, while the gunproduced plasma appears to be well 
focused, the actual beam quality must be measured more accurately to determine whether it meets requirements.

Recently, Prono has obtained encouraging though preliminary results with a new fon source concept that should work in the energy range of $100 \mathrm{keV}$ or more and that could be the basis of a pulsed neutral injector delivering a thousand or more tim-s the current obtained from present sources (see Appendix F). Thus far, Ions have not been extracted; this is the next experiment. If these tests give positive results (for example, concerning beam quality), this new source should be developed as rapidiy is possible both for the purposes discussed here and for wider usage in CTR research.

Otherwise, since the magnet design does not appear to be a critical issue, research on the reversed-field mirror configuration would likely follow as a matter of course using the mainline facilities through the $\mathrm{MX}$ phase.

However, the reversed-field pussibility does give added impetus to the development of less costly magnet designs, as discussed in the next section. The combination of field reversal and a low-cost, simple-mirror magnet could well be that tour de force that would make a small, cheap, mirror fusion reactor feastble.

\section{Field Optimization and Simple Mirrors}

The direct contribution of tite Yin-Yang magnet to the cost of the present DT mirror reactor reference design ranges from $15 \%$ to as high as $25 \%$, depending on what type of support structure turns out to be necessary. A simpler design compatible with MHD stability could reduce these direct costs considerably and might allow greater flexitility in the design of other components that would further improve upon the capital cost picture. Moreover, a simpler coil system would surely save time and money in the development, :iase. We propose to utilize $2 \mathrm{XC}$ in experiments toward these ends. The 2Xa, now proposed to be built in FY 1977, would be a further modification of the $2 \mathrm{X}$ facility. Only the magnet and vacuum chamber would be replaced, while all 2XIlB power supplies, neutral beams, diagnostics and controls would be reused. Thus, the cost would be quite modest (see Appendix G). 
The 2XC magret would consist of two independent coil sets as sketched in FIg. G-1. The outer "cee-shaped" magnets would be used to spoil the minimum-B fleld created by the inner lin-Yang pair and therefore would permit the experimenter to create a wide variety of field shapes ranging from unstable conflgurations to minimum-B and gradations between. An important theoretical tool to be used in these optimization studies Is the I.LL three-dimensional equilibrium and MMD stability code that is now operational and giving first results at finite beta.

One of the important questions along these lines is the possibility of returning to the simple mirror stablized by line tying. Recently,
LI.I. prepared a report on the current status of this problem. ${ }^{10}$ The report suggests that, unless feedback is added, a plasma at the ends in sufficient contact with the walls to provide line-tying across the whole machine cross section would necessarily present an unacceptable heat leak (except in the twocomponent mode). Since then, other posstbllties have been considered in which line tyling would occur only over a thin surface where the hot piasme ( $\Delta p=0$ inside) would be in contact with a shell of low-temperature plasma that would provide the necessary contact to the ends. Many questions remain, some of which may be answered in 2XIIB experiments.

\section{Mirror-Torus Hybrids}

Several promising mirrer-torus hybrld posstbilities are already being pursued, such as the Tormac at Lawrence Berkeley Laboratory (LBL) and the Elmo Bumpy Torus (EBT) at Oak Ridge National Laboratory (ORNL). While we plan to follow closely the work of other laboratories in this area with the possibility of cooperative work in the future, we have no immediate plans.
We find that a major issue is the relatively large cost of all but the simplest toroldal configuration. For this reason, a bumpy torus composed of simple mirrors, such as EBT, is espectally attractive. As a complement to the EBT employing electron cyclotron heating, it may be possible to base such a configuration on neutral Injection and stability of mirror-confined hot ion components 
stabilized by line tying to limiters at the plasma surface, as discussed above. If so, the first step would be an experiment with a singie, simple-mirror cell. Alternatively, 2XC could provide the data. Then, if a single cell could be stabilized, one could proceed directly to construce such an Ion Bumpy Torus (IBT) based on neutral injection. Again, by sharing mainline mirror program facilities, costs to develop this new configuration need not be prohibitive.

In reaching our conclustons on mirror torus hybrids, we have examined several different geometries. Following the work of Chris Watson at Culham, ${ }^{11}$ we have re-examined a toroidal configuration of linked, minimum-B mirrors. A rough parameter analysis is glven in Appendix $H$. Knowing the relatively high cost of Yin-Yang magnets, we first looked Into simpler shapes, but in the end we agreed with Watson that back-toback Yin-Yang magnets provide the best means of leading the diverging flux: from one mirror cell into the next. However, the cost is hIgh because of the high field and high ellipticity of the connecting toroldal sections. Consequently, capital costs fur such a reactor appear to be high, though within a reasonable range for future power needs. Intermediate experiments would be expensive. To be meaningful, a minimum experiment would probably be the equivalent of a dozen Baseball II machines.

We have also examined the possibility of a two-component mirror system in which a "simple" toroldal return would contain a dense Maxwellian component threading through a single, minimum-B mirror cell. Again, matching the diverging flux bundles to the toroldal loop proved to require an extra patr of Yin-Yang windings, and this single-cell case also requires very high values of $n t$ in the coroidal section (see Appendix H).

Besides the above concepts in which the toroldal nature is dominant, McNamara and Hall have suggested that a small toroidal loop be used to recirculate electrons at a density $10 \%$ or so of the hot plasma density. 12 The motive is to produce a small improvement in $Q$ (see Section 3). Cornell has proposed carrying out such an experiment (MIRICLE). 


\section{Long Linear Machines}

Primarily motivated by the twocomponent mirror concept, we have examined several magnetic configurations that might serve as a fusion engineering research facility (FERF) in a relatively smali size and project to reactors in large sizes. In the two-componont infror, a dense, tritium, Maxwelltan plasma flows freely along the axis of a mirror system that confines hot deuterons supplied hy neutral injection.

This class of ideas poses fewer stability issues than any of the foregoing concepts. Concerning microinstability in particular, the 2XIIB experiments are very encouraging on this point, and experiments more speclfically apolicable to the two-somponent reglme are planned for the future.

A major problem is a requirement for high beam power to do convincing experiments. A full two-component experiment in 2XIIB is expected to $y$ leld an $n t$ about 10 times less than that already achieved. Following the simple two-component approach, a breakeven experiment would require a gigawatt or more of beam power (but only for a few milliseronds. 13 Another problem is the field design to maintain MHD stability in the mirrors at the end of a long, thin column: however, line tying might serve.

Again, we are watching developments in this area with interest, but have no immediate plans beyond what can be done in existing experiments, For now, we are maintaining much the same position with respect to multiple mirrors; some members of the LLL staff are studying reactor applicatlons of multiple mirrors, and we cooperate with the U.C. Berkeley group in this area. ${ }^{14}$ We are also following with interest the work of Jawson and others on end plugs that could reduce the length of long solenoid raactors (with mirrors only to confine the Ion beans injected for heating).

\section{Summary}

The inain-Iine mirror progran at LLL defines an approach to fuston power that we feel possesses many advantages. In this report, we have discussed some present thinking on ways to more fully exploit these bas ic advantages through modifications motivated by nhysics or economic 
considerations. The approaches discussed range from simple optimization of the magnet colls to speculations on the possibility of producing mirrorconfined, reversed-fleld, plasma configurations. That we can contemplate such a wide range of posstbilities
Is a consequenre of the inherent flexibility of the mirror approach. We feel that this flextbilicy, this avallability of options for Improvement, is a most important asset in achieving the goal of a viable fuston reactor at the earliest possible date. 


\title{
Appendix A: Comparison of Experimental and Theoretical Limits on Beta
}

\author{
M. E. Rensink
}

Theoretical estimates of the beta where limil in 2 XIIB have been based on the MHD (zero-Ryroradius) stability condition for the mirror instability,

$$
G(\varepsilon)=e^{-\varepsilon}\left[I_{0}(\varepsilon)-I_{1}(\varepsilon)\right],
$$

and

$$
\begin{aligned}
\varepsilon+\frac{d p}{d B}>0, & =L_{5}\left(k_{\perp} a_{1}\right)^{2} \\
I_{0}, I_{1} & =\text { Bessel functions. }
\end{aligned}
$$

and in the long, thin plasma equilibrlum model,

$$
P_{\perp}+\frac{1}{2} B^{2}=\frac{1}{2} B_{\text {vac }}^{2} .
$$

For highly anisotropic velocity distributions as deduced from experimental measurements of the axial density profile or from Fokker-Planck calculations, this theoretical model predicts $\beta_{\max }=0.20$, whereas experimental observations yield $\beta_{\max }=0.40$.

This discrepancy may be partially explained by the fact that the theoretical model does not include the effects of finite gyroradius and fieldline curvature.

The modification of the mirror instability beta limit by fintte gyroradius effects has been treated by Furth. 15 For an infinite, homogeneous plasma with ion distribution characterlzed by two unequal temperatures $\left(T_{1} \gg T_{\mid l}\right)$ the beta limit is given by

$$
\beta_{\max }=\frac{1}{G(\varepsilon)}\left(\frac{T_{i} i}{T_{\perp}}\right) \text {, }
$$

Here $k_{1}$ is the perpendicular wavenumber of the instability and $a_{1}$ is the ion gyroradius. In the zerogyroradius limit, we have $G(E) \underset{\epsilon \rightarrow 0}{\longrightarrow}$, and the maximum stable beta is

$$
B_{\max }=\frac{T_{1}}{T_{1}} \text {. }
$$

In a finte-gyroradius plasma of finite radial extent, one has

$$
k_{\perp} a_{1} \geq a_{i} / R_{p},
$$

where $R_{P}$ is the plasma radius; therefore, in 2 XIIB where $a_{1} / R_{p} \sim \frac{i}{5}$, we may have $E \sim 1 / B$, and the beta limit becomes

$$
\beta_{\max } \approx 1.25\left(\frac{\mathrm{T}_{1}}{\mathrm{~T}_{\perp}}\right) \text {. }
$$

a 25\% Increase due to fintte gyroradius. In a more extreme situation where $k_{\perp} a_{1}-1$, the maximum beta is increased by almost a factor of 2 over the zero-gyroradius result. The 
precise form of the ion velocity distribution is an important factor in :hese beta estimates. For example, she two-temperature Maxwellian analyzed by Furth gives $\beta_{\max } \approx T_{i \mid} / T_{\perp}$ whereas a norma1-mode loss-cone distribution ${ }^{16}$ gives $\beta_{\max } \approx 2 \mathrm{~T}_{i \mid} / \mathrm{T}_{1}$. The finite-gyroradius corrections need to be calculated for more realistic ion distribution functions.

A modification of the mirrer instability beta limit by fleld-1ine curvature effects has been given by Rose. ${ }^{17}$ For an infinttely long homogeneous plasma of finite radius $R_{p}$ with ion distribution characterized by two unequal temperatures $\left(T_{1} \gg T_{11}\right)$, the beta Iimit is

$$
\beta_{\text {max }}=\left[1+\frac{\lambda k_{0}(\lambda)}{2 k_{1}(\lambda)}\right] \frac{T_{\|}}{T_{\perp}} .
$$

where

$$
\begin{gathered}
\lambda=k_{\mid l} R_{p} \\
k_{0}, k_{1}=\text { Hessel functions. }
\end{gathered}
$$

Here $k_{\text {I }}$ is the parallel wavenumber of the instabllity. In the long, thin plasma limit $k_{\mid i} R_{p} \ll 1$, this reduces to the simple criterion

$$
B_{\max } \approx \frac{\mathrm{T}_{1}}{\mathrm{~T}_{l}}
$$

In a plasma of finite axial extent (hence, finite parallel wavelength), one has

$$
k_{1 !} R_{P} \geq R_{P} / L_{p},
$$

where $L_{p}$ is the axial scale length, so that in $2 X I I B$ where $R_{p} / L_{p} \sim \frac{1}{2}$, the beta limit would become

$$
\beta_{\max }=1.14 \frac{T_{11}}{T_{1}}
$$

In the case of a spherical plasma where $R_{p} / L_{p} \sim 1$, the value of $\beta_{\max }$ would be increased by about 35\% relative to the long, thin plasma result. The curvature for the equilibrium fleld lines has not been included in this analysis, but it is 1ikely that this will produce an additional stabilizing effect on the mitror instability. 


\title{
Appendix B: Q-Enhancement by Programmed Neutral Injection
}

\author{
R. F. Post
}

INTRODUCTION

Suppose that prugrammed neutral infection can be used to create a sequence of high- $\beta$ equilibrium states in a mirror system where the distance between the mirroring polints for the previously trapped particles increases with time. Thts action corresponds to reflection from receding mirrors, resulting in a loss of parallel energy from each particle upon reflection, i.e. cooling of $\mathrm{w}_{1}$; by longitudinal expansion. During the time this process can be maintained, the rate of loss of particles through the mirrors will be reduced as a result of slowing of the rate of diffusion into the loss cone (which is caused by increasing $W_{\|}$). Simultaneously, the reacting volume will increase as more and more particles are injected and thereby dig a longer and longer mirroring region by virtue of their localized $P_{f}$. We wish to estimate the order of magnitude of the quantities involved to see if a significant reduction in end losses (hence a lengthening of mean residence time of the lons) could be expected. If so, one could expect an enhancement of the $Q$ value of the system through Increasing the probability of reaction of the average ion before 1 t.s loss. Two circumstances help here:

\section{- Collisional diffusion} involves three spatial cocrdinates, whereas particle losses are most directly to be assoclated with an increase in only one of the three $\left(w_{1}\right)$.

- The large $\gamma$-factor associated with one-dimensional expansion preferentially removes $w_{||}$, as compared to a two- or three-dimensional expanston process.

ESTIMATE OF REQUIRED EXPANSION TIME SCALE

We shall assume that a significant effect $w 111$ be observed if the rate of decrease of $W_{\mid l}$ by longitudinal expansion equals or exceeds the mean rate of population of $W_{\mid l}$ through collislonal diffusion, taking into account that diffusion into the $w_{1}$ component is generally required for loss to occur. This condition can therefore be written approximately as

$$
\left|\Delta W_{\mid I}\right| \cdot v_{R} \geq\left|\frac{d W_{\mid l}}{d t}\right| \approx \frac{1}{3}\left(\frac{W_{E}}{\tau_{E}}\right)
$$


Here $v_{R}$ is the rate of reflection of particles from the outwardly moving mirrors, each reflection resulting in a reduction in $w_{1}$, of magnitude $\Delta W_{\mid}$; and $\tau_{E}$ is the usual ion-ion collisional relaxation rate for diffusion in energy (a la Spitzer).

From an elementary calculation, we find that

$$
\Delta \mathrm{w}_{11}=2 \mathrm{M} \mathrm{v}_{1} \mathrm{v}_{\mathrm{m}}
$$

where $v_{m}$ is the velocity of recession of the mirroring points. Also

$$
v_{R}=\frac{v_{1} !}{L(t)}
$$

where $L(t)$ is the (time-varying) distance between the mirroring points. As usual we can write

$$
\begin{aligned}
n \tau_{E} & =\mathrm{K} \mathrm{w}^{3 / 2} ; \\
\text { i.e., } \quad 3 \tau_{E} & =3 \mathrm{~K} \mathrm{w}^{3 / 2} / \mathrm{n} .
\end{aligned}
$$

Inserting Eqs. (B2), (B3) and

(B5) into Eq. (B1), we obtain

$$
\frac{2 M v_{\|}^{2} v_{m}}{L(t)} \geq \frac{w \cdot n}{3 k w^{3 / 2}} ;
$$

1.e.

$$
\frac{4 w_{\|} \cdot v_{m}}{L(t)} \geq \frac{n \cdot w}{3 k w^{3 / 2}} .
$$

Note that the condition becomes easter to satisfy for these particles that have gained $W_{\mid l}$, thus lending to a tendency to clamp thefr parallel energy.

$$
\begin{aligned}
& \text { If we write } \dot{\mathrm{L}}=2 \mathrm{v}_{\mathrm{m}}, \\
& \text { then } \begin{aligned}
\frac{\dot{\mathrm{L}}}{\mathrm{L}} \geq & \frac{1}{6}\left(\frac{\mathrm{n}}{\mathrm{kW}^{3 / 2}}\right)\left(\frac{\mathrm{W}}{\mathrm{w}_{\mathrm{H}}}\right), \\
\text { or } & \frac{\dot{\mathrm{L}}}{\mathrm{L}} \geq \frac{1}{6} \frac{1}{\tau_{E}}\left(\frac{\mathrm{W}}{\mathrm{W}_{1}}\right) .
\end{aligned}
\end{aligned}
$$

Integrating the equality

$$
\begin{aligned}
& \frac{L}{L_{0}}=e^{c t}=1+c t+\ldots ; \\
& c=\frac{1}{6 \tau_{E}}\left(\frac{W}{W_{1}}\right),
\end{aligned}
$$

from this it follows that the required condition is, approximately,

$$
\frac{L}{L_{0}} \approx 1+\frac{1}{6}\left(\frac{t}{T_{E}}\right)\left(\frac{W}{W_{\mid}}\right) .
$$

In other words, if the length between the mirrar points doubles on a time scale shorter than a few times $T_{E}$, a mafor influence on collisional end logses should be observed. Alternatively, one might hope to compete with a loss rate that is enhanced over classical rates by employing axial expansion rates that occur on about the classical loss-time scale. The above calculations simply indicate that a significant influence on end-loss rates could be hoped for with programmed neutral injection (or some similarly acting process) that causes the mirroring points to recede 
from each other on a time scale that might be as long as a few times the classical energy exchange rate. To find the $Q$ enhancement actually achievable would require a transient Fokker-Planck code run. One might guess that an overall factor of 2 gain (integrated reaction yield divided by integrated beam energy input) is posstble.

The process of axial expansion proposed involves exchanges of energy with the confining field. To the extent that these exchanges are reversible, at the end of the process, when the reflection points will presumably collapse back toward the midplane, energy will be transferred to parallel particle motion and to the magnetic field. Presumably, these phenomena can be utilized to advantage in the dfrect conversion processes assoctated with the reactor operation. 


\title{
Appendix C: Analysis of the Kurchatov Reversed-Field Experiment
}

\author{
C. W. Hartman
}

Kurtmullaev and his co-workers are studying a long-lived toroldal Z-pinch formed by the relaxation of a reversed-field $\theta$-pinch ${ }^{8}$ (see FIg. C-1). In addition to the usual $\theta$-pinch, a pulsed, octupolar "barrier" fleld is applied to prevent plasma contact with the walls during programmed field reversal. The barrier field may also affect the stability of the toroidal $z$-pinch. has been determined experimentally : no toroidal flux is trapped in the pinch.

The toroidal pinch has the following parameters: $R \approx r_{p} \approx 3 \mathrm{~cm}$, axial length $Z_{p} \approx 2 r_{p}, B \leqslant 0.45 T$, $\mathrm{T}_{\mathrm{e}} \leq 500-1000 \mathrm{ev}, \mathrm{T}_{1} \leqslant 16 \mathrm{c}-200 \mathrm{eV}$, and $n \leq 1 i^{95} \mathrm{~cm}^{-3}$. It is long lived only if the current layer is sufficiently diffuse and its diameter is sufficiently laige, and then it lasts up to $\tau \leqslant 50 \mu s$. Since this lifetime corresponds to several hundred transits of sound across $r_{p}$, MrD stability is apparently achieved. Also. since the lifetime corresponds to 10 or possibly more Bohm times, microinstability is apparently weak.

Al though, Newcomb's energyprinciple analysis of hydromagnetic gtability of a pureiy poloidalfield toroldai pinch dnes not yet preclude stability, indlcations are that stable states are unlikely. To explain the observed stability, other effects may be important, especially fintte ion gyroradius and possibly barrier field trapped in the plasma.

To the extent that the toroidal [inch can be approximated by a straight 2-pinch, three ideal MHD Instability modes a: a predicted: 18 sausage instability, kinking of the whole column, and internal kinking. The necessity of achieving a diffuse current layer to obtain long life suggests reduction of the sausage mode growth rate as predicted by the the $y$, where stability occurs if $-d\left(\ln p_{j} / d(\ln r)<4 \gamma /(2+B \gamma)\right.$, $\beta=p /\left(B^{2} / 2 \mu_{0}\right)$. Near the boundary, where the stability condition is violated, finite-Larmor-radius (FLR) or line-tying effects may give stability. The absence of kinking of the whole column $1 \mathrm{~s}$ perhaps credibly explained by the diffuse nature of the pinch, by nearby walis, and/or by the sma11 aspect ratio $R / r_{p}$. This leaves internal kinking modes $(m=1)$ 
with radial localization as the remaining $\mathrm{MHD}$ instab1licy. As shown in Ref. 18, 1nternal kink modes are presen: in the central region where $\beta \geq 1$, and they are not stabilized by a diffuse pressure profile. This persistent instahility also appears in tokamaks if $q<1$ in the incerior.

A rough estimate of ion Larmor radius for the experiment car be obtained by noting that if $I$ is the pinch current and $S=r_{p} / a_{i}$, then

$$
I(A)=1000 \mathrm{sT}_{1}^{1 / 2}(\mathrm{eV}) \text {; }
$$

and from the Bennett relation, $I^{2}(A)=10^{-9} n\left(\mathrm{~cm}^{-3}\right) r_{p}^{2}(\mathrm{~cm})\left(T_{i}+T_{e}\right)(e V)$.

so that $S$ is given by,

$$
\mathrm{s}^{2}=\frac{\mathrm{nr}{ }_{\mathrm{p}}^{2}}{10^{15}} \frac{\mathrm{T}_{\mathrm{e}}+\mathrm{T}_{1}}{\mathrm{~T}_{1}} .
$$

Taking $r_{\mathrm{p}} \approx 3 \mathrm{~cm}, \mathrm{n} \approx 5 \times 10^{14}$, and $\mathrm{T}_{\mathrm{e}} / \mathrm{T}_{\mathrm{i}} \approx 5$, gives $\mathrm{S} \approx 4$ for hydrogen.

To estimate the importance of FLR effects on stability, allowance must be made for the noncircular crosssection (see Fig, $\mathrm{C}-1$ ) and for the fact that the incernal $\beta>1$ region has dimensions smaller than $r_{p}$. Roughly speaking, however, an equivalent $S$ is probably in the range 1 to 10. Since the internal kink modes are localized radially, $k_{\perp} \geq k_{r}$ and values of $k, a_{i} \simeq k r_{p} s$ may be of order unity; thus leading to FLR stabilization.

No adequate stability theory is avallable for 7-pinches or for the small aspect ratio toroidal pinch of the experiment for which $\beta$ and the ion gyroradius are both large and where strongly unstable fluid modes are present. For weakly unstable systems with low $B$, FLR stabilization occurs roughly when $\omega^{*} \approx Y$, where $\omega^{*}$ is the dtamagnetic drift frequency, and $\gamma$ is the fluid growth rate. The $\mathrm{m}=1$ kink instability has $\gamma \approx \mathrm{k}_{\mathrm{z}} \mathrm{V}$ Alfyen " ind since $\omega^{*} \approx k_{2} V_{\text {sound }} a_{1} / r_{p}$ stability of kink modes is by analogy suggested when $a_{i} / r_{p} \geqslant V_{A} / V_{S}$ $\approx 1 / \sqrt{ } \beta$. This passibility has been noted earlier ${ }^{19}$ in connection with the absence of kinking in the plasma focus. 


\section{PLASM COHPIBEXEST IN A YUZSED SYSTEX WITH A} SOLPACT TOROIDAL COHPIGUA ATION

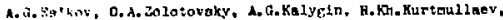

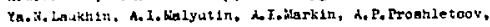
Y. ה. Sertemov

Kirchatov lighitute of Atoric Enerey, Noscov,uSSh

swe nojeful reaulte of phock iseatinf nud otable confinement by a irelir pololdel field were obialned wh th thes belng subgtartially

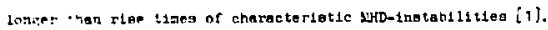

Dircher tevelopent or theor experiments lo presented in thls work.

The axperlizen:日 wh: carried out with a opineh davice $18=4,5 \mathrm{kG}$,

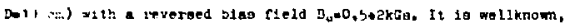
tia. : iatia sxpartion to wallo at the intilal otace of discharge

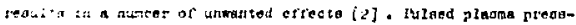
1:2* odt : :wr. the wall by tenne of a harrier ileld during this otaga

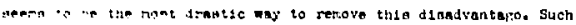

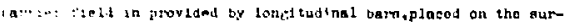

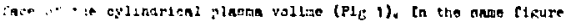

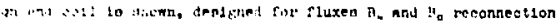

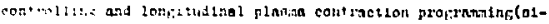
: : :at?.

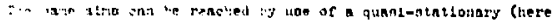
DC.

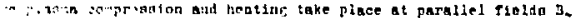

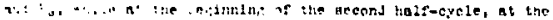

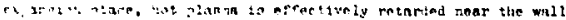

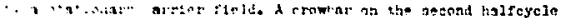

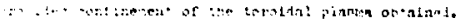

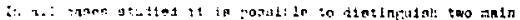

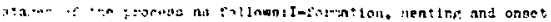

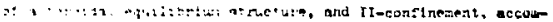

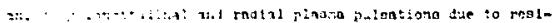

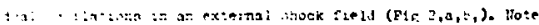

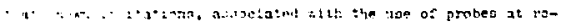

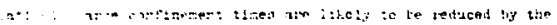

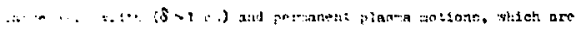

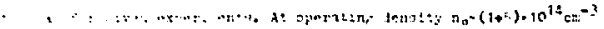

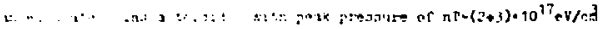

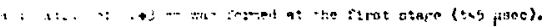

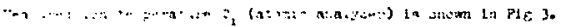

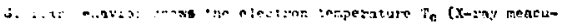

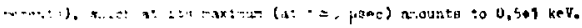

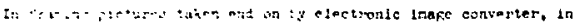

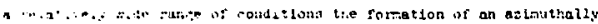

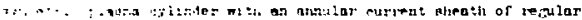
$\because+\cdots+n, \quad, \cdots=1(p \leq 4, n)$.

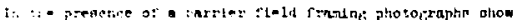

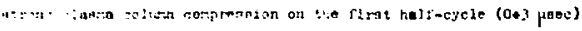

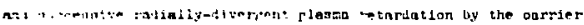

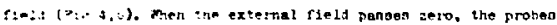

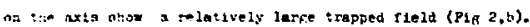

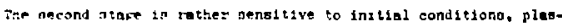

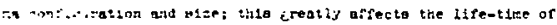

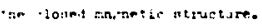

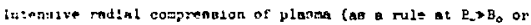

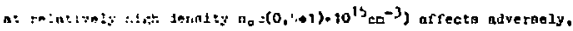

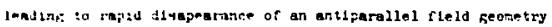
$(i=10$ rians)

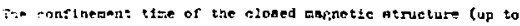

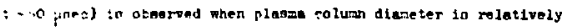
iare $(0, / D \div 0,3 \bullet 0, \theta)$ and current whenth to greately difruaed being of the order of planis radius. In conventionel oxperimental achome

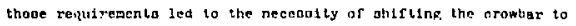
the point, lying нuthetantially below the maxtmun of the pulaed megretic riold b. This reoulted in a plagno preasuro decreade by an ordor of negnltude. Voe of a pasolve (ntationary) barrier rleld didn't allow to avoid thite difficulty, oince the crowbir on tho atcond half-syclo wauced, to iarpe extent, a conrinlag c10lo. $A$

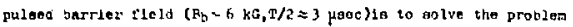
or otable confinerent olmulimooualy providing aubatantiel increnge or enerey content in a suarna.

Heasuremonte of the artiruthal. component $B_{0}$ indicaten $n$ the

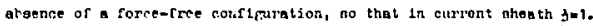

It ahould be notrd, that the clobed pasnetse otinjelure liftelime obuerved la rather hopeful for a "O-pinch with lina" appliga-

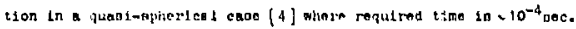

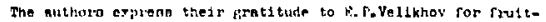
rul d I Geugrionn."

\section{Reterenceng}

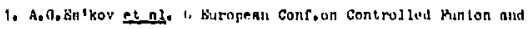

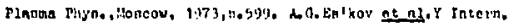

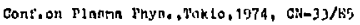

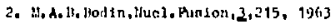

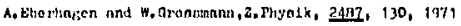

3. A. a. Bg'koy sl al. b buropean Gons.on Bontrollod Funton and flang lhy, , hoocow, 19\%3, p. Syr,

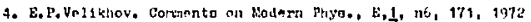
R. Kh. Kurtmullnov and d. K.Malyutin. dld-Jnlon Jymig. on

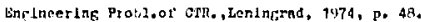
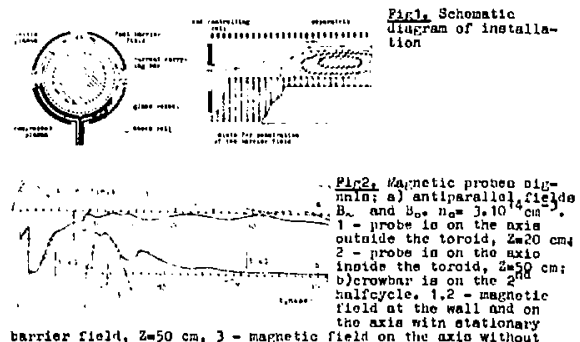

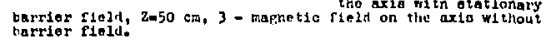
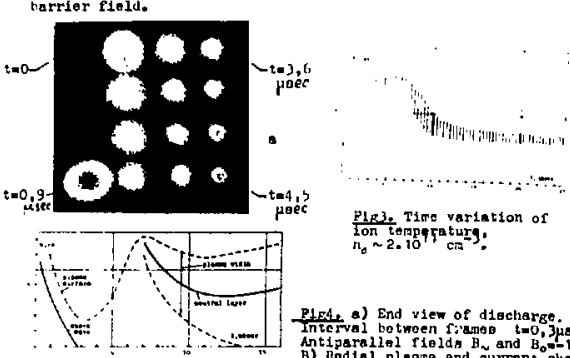

Plal. Tire variation of Ton terpqcitury:

P1E4, a) End view of discharge. Intcrval botwoen $r j$ meb tao, 3jo, A) Radial plaome and eurront ohoath position, obtainea rrom ond pictareo. Growbar is on the $2^{\text {nd }}$ halreycle, ${ }_{0}=1 \mathrm{kG}$, wh ih atallonery

Fig. C-1. Reproduction of Ref, 8 . 


\title{
Appendix D: Reactor Potential of Reversed-Field Mirror Configuration
}

\author{
W. C. Condit and T. K. Fowler
}

In Section 4 of the main text, it was suggested that a reversedfield configuration in a mirror machine might be stabllized by finite-orb1t effects, together with an aspect ratio near unity (see also Appendix C.).

Assuming this as a working hypothesis, we have considered briefly what a reactor might look like.

The concept is sketched in Figs. $D-1$ and $D-2$. In the absence of $a$ quantitative theor', let us assume $a / \rho_{1}$ to be a small integer (10 or less) and $R_{p} / a=1$ to 2 , where $\rho_{i}$ is the fon Larmor radius, and $R_{p}$ and $\underline{a}$ are the major and minor radil of a (short) cylindrical plasma "doughnut". The plasma density w11 be nonuniform, represented by a parameter $f=\bar{n}^{2} / n_{0}^{2}$. The fustun power per unit length would be

$$
\begin{gathered}
\frac{P}{\mathrm{~L}}=\frac{E}{4} n^{2} \cdot \overrightarrow{\sigma v} \cdot \mathrm{E}_{\text {nuc }} \cdot \pi \cdot\left[\mathrm{R}_{\mathrm{p}}+\right. \\
\left.\mathrm{a})^{2}-\left(\mathrm{R}_{\mathrm{p}}-\mathrm{a}\right)^{2}\right] .
\end{gathered}
$$

Substituting $\mathrm{E}_{\text {nuc }}=17.6 \mathrm{MeV}$, 2n $T_{i}=\beta B^{2} / 8 \pi$, and writing lengths in units of the deuteron $\rho_{1}$, with a constant $K=M_{D} \cdot E_{\text {nuc }} / 128 \pi q^{2}=$ $57.2 \times 10^{16} \mathrm{keV} / \mathrm{cm}$ :

$$
\frac{\mathrm{P}}{\mathrm{L}}=\mathrm{K} \cdot \mathrm{f} \cdot \mathrm{B}^{2} \mathrm{~B}^{2}\left(\frac{\mathrm{a}}{\rho_{1}}\right)^{2} \frac{\mathrm{R}}{\mathrm{a}} \frac{\overline{\sigma v}}{\mathrm{~T}_{\mathrm{i}}} \cdot(\mathrm{D} 2)
$$

For a Maxwellian distribution, $\overline{\sigma v} / \mathrm{T}_{1}$ for DT reactions is constant at 2.2 * $10^{-17} \mathrm{~cm}^{3}$ per $\mathrm{keV} \cdot \mathrm{s}$ for $\mathrm{T}_{1}$ between $15 \mathrm{keV}$ and $35 \mathrm{keV}$ to within $10 \%$. Then, In this range and taking $a / \rho_{1}=10, R_{p} / a=2, B=1$, and $\lambda$ and $f=8 / 15$ for a parabollc profile, we obtain

$$
8.3 \frac{\mathrm{MW}}{\mathrm{m}}<\frac{\mathrm{p}}{\mathrm{L}}<33 \mathrm{MW} / \mathrm{m}
$$

for

$$
2.5 \mathrm{~T}<\mathrm{B}<5.0 \mathrm{~T} \text {. }
$$

While it has disadvantages, the lower field is to be preferred for beam infection reasons: assuming the beams will be aimed tangent to the radius at the field null $\left(R_{p}\right)$, the thickness of the plasma traversed by the beam is $2 \sqrt{5} a$ for $R_{p}=2 a$. We shall choose the product of thickness and density to $11 \mathrm{e}$ between $1.5^{*} 10^{16} / \mathrm{cm}^{2}$ (the FERF value from Ref. 20 for $60-\mathrm{keV}$ Injection) and $2^{*} 10^{16}$ (for 200-keV injection, per Ref. 13). At $2.5 \mathrm{~T}$, 
we get the following parameters for $\mathrm{T}_{\mathrm{e}}=\mathrm{T}_{1}=30 \mathrm{keV}, \beta=1$ :

$$
\begin{aligned}
\mathrm{T}_{\mathrm{e}} & =30 \mathrm{keV} \\
\mathrm{B}_{0} & =2.5 \mathrm{~T} \\
\mathrm{n}_{\mathrm{e} O} & =2.6^{*} 10^{14} / \mathrm{cm}^{3} \\
\rho_{\mathrm{D}} & =1.41 \mathrm{~cm} \\
\mathrm{a} & =14.1 \mathrm{~cm} \\
\mathrm{R}_{\mathrm{p}} & =28.3 \mathrm{~cm} \\
2 \sqrt{5} \mathrm{n}_{\mathrm{e}}^{\mathrm{a}} & =1.65^{\star 10} 10^{16} / \mathrm{cm}^{2}
\end{aligned}
$$

This value of $2 \sqrt{5} \mathrm{ne}_{\mathrm{e}}$ is conventent for beam penetration. Stronger fields and lower temperatures would make beam penetration more difficult. Higher temperatures, coupled with moderate increases in $B_{0}$ (say $B_{0}$ proportional to $\sqrt{T_{i}}$ ) would leave the density and the dimensions unchanged, yet increase the power per unit length proportionally to $\overline{\sigma v}$ from Eq. (D2). As will be shown below, this will require higher wall loadings. However, the higher temperature reduces technological problems (mainly vacuum problems) related to charge exchange, so the actual parameters selected for a reactor would be a compromise between wall loading and other considerations. Finally, the diffuse plasma profile, mentioned in Ref. 8, will permit additional field (and density) increases, and ostensibly wtll make the vacuum problems easter. The wall radius must be placed two alpha gyroradil beyond the plasma boundary at $R_{p}$ ta - this gives a wall radius of $64 \mathrm{~cm}$. At a fusion power of $8.3 \mathrm{MW} / \mathrm{m}$, the wall would have a neutron flux of $1.7 \mathrm{MW} / \mathrm{m}^{2}$ for the $2.5 \mathrm{~T}$ case, a conventent level at whlch to operate.

We imagine a reactor as consisting of a number of independent modules. An example set of machine parameters for a single module, based on Eq. (D4), Is given in Table D-1. Note there, and In Fig. D-1, that we have incorporated a multipole fleld provided by Ioffe bars. In the table, the Ioffe bar current corresponds to the conservative assumption that the Ioffe fleld is a quadrupole with a field strength equal to the main field at a radius of $R_{p}+a$. It remains to be seen whether such a field is actually needed in the steady state, and, if so, how strong it must be.

An alternate set of parameters, with higher temperature and somewhat higher wall loading, is given in Table D-2. Note that these parameters yleld a higher power output. These were arrived at by scaling up the magnetic field and temperature (as described after Eq. (D4) above) and taking advantage of the small but noticeable increase in beam penetration for higher-energy injection. We have omitted the Joffe bars from 
this parameters set, because, again, we are not convinced that they are essential.

Whether such modules could form the basis of an economical reactor is now under study. A preliminary estimate Indicates that the economics will be favorable if no Ioffe bars are needed, but marginal for the Ioffe currents shown in Table D-1. The system might consist of one or more linear chains of independent mirror cells linked end to end. To maintain a neutron flux of a few $\mathrm{NW} / \mathrm{m}^{2}$, the first wall radius would be 0.5 to $1 \mathrm{~m}$. Thus, one might imagine a single cell about the physical size of $\mathrm{MX}$ ( $L=3.6 \mathrm{~m})$, but with circular colls. It is obvious that the combination of simple coils and enhanced plasma confinement should have a favorable impact on reactor economics.

The picture of a small, medtumfield reactor cell lends itself to modularized construction. Moreover, since each relatively small cell is self-contained as far as its plasma confinement properties are concerned, development costs should be greatly reduced. However, again we stress the speculative nature of the entire concept at this time. 


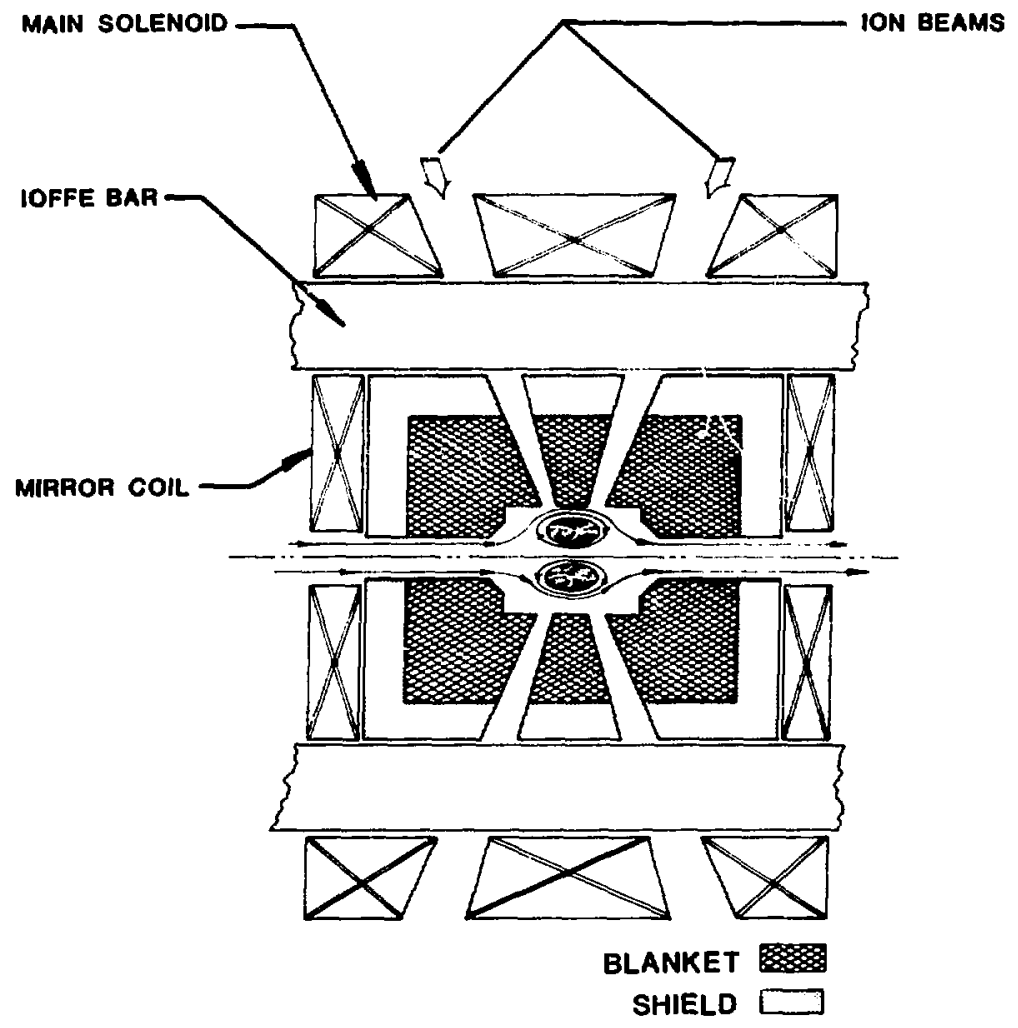

F1g. D-1. Reversed-field mirror reactor: side view. 


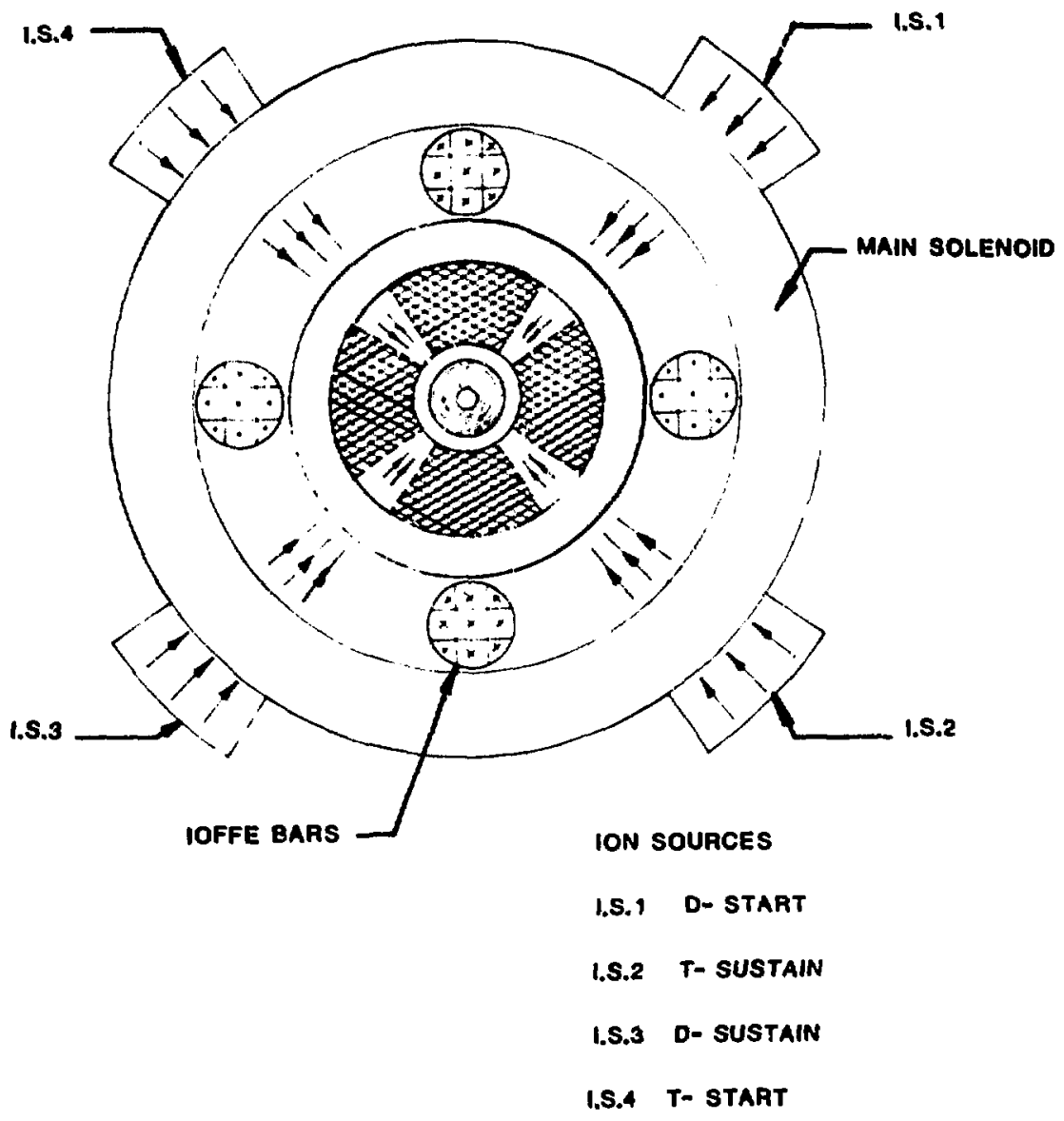

Fig. D-2. Reversed-field mirror reactor: end view. 
Table D-1. Machine parameters for reference case reversed-fleld $\pi$ rror reactor

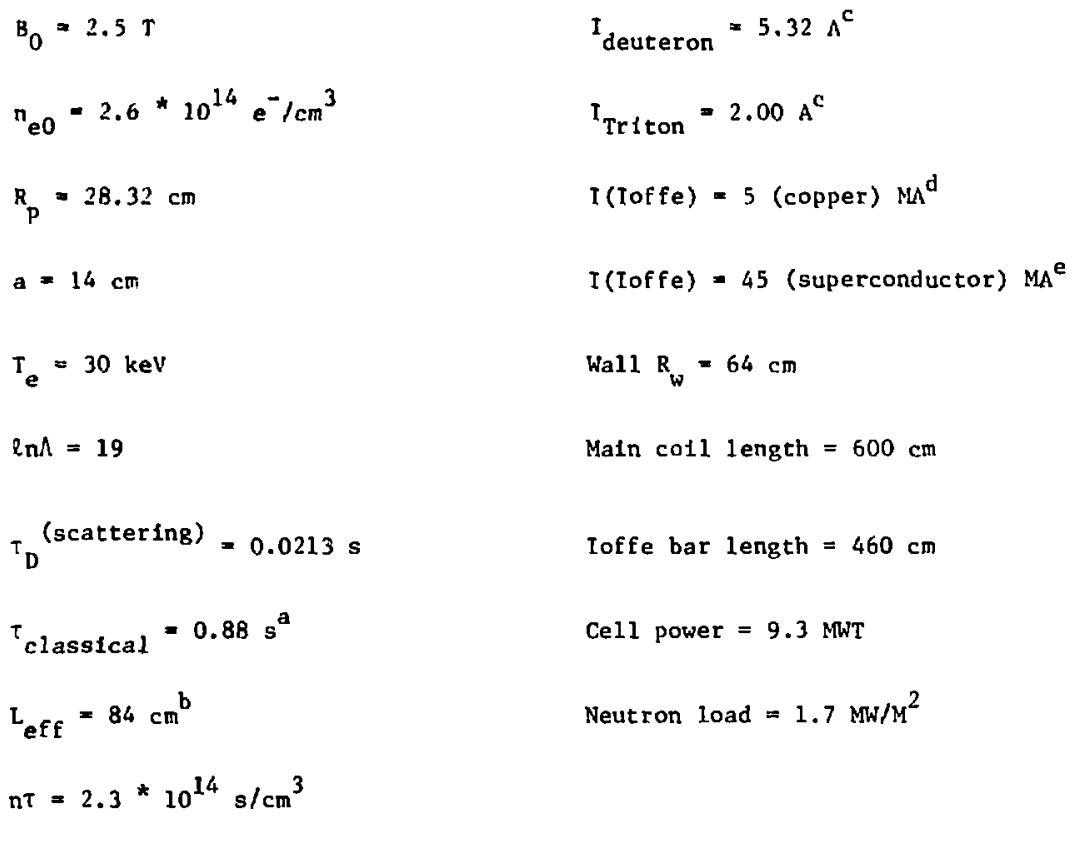
${ }^{a} \tau_{\text {classical }}={ }^{\tau}{ }_{D D} \cdot a^{2} / 2.4 \rho_{D}^{2}$
b $L=3 R_{P}$
C Spl1t per Ref, $20\left(I_{T}=0.034 I_{D}\right)$
d Centered at $85-\mathrm{cm}$ radius
e centered at $250-\mathrm{cm}$ radius 
Table D-2. Machine parameters for improvad-case, reversed-field mirror reactor

$\mathrm{B}_{0}=4.5 \mathrm{~T}$

$n_{e 0}=2.6 * 10^{14} \mathrm{e}^{-} / \mathrm{cm}^{3}$

$R_{p}=34.8 \mathrm{~cm}$

$a=17.4 \mathrm{~cm}$

$T_{e}=100 \mathrm{keV}$

$\ln \Lambda=20$

$\tau_{\mathrm{DD}}{ }^{\text {(scattering) }}=0.124 \mathrm{~s}$

$\tau_{\text {classical }}=5.18 \mathrm{~s}^{\mathrm{a}}$
$L_{\text {eff }}=174 \mathrm{~cm}^{b}$

$\mathrm{nt}=1.3 * 10^{15} \mathrm{~s} / \mathrm{cm}^{3}$

$I_{\text {deuteron }}=2.79 \mathrm{~A}^{\mathrm{C}}$

$\mathrm{I}_{\text {Triton }}=1.04 \mathrm{~A}^{\mathrm{c}}$

Wall $\mathrm{R}_{w}=64 \mathrm{~cm}$

Cell power $=33 \mathrm{MWT}$

Neutron load $=3.0 \mathrm{MW} / \mathrm{m}^{2}$

Triton radius $=1.74 \mathrm{~cm}$

\footnotetext{
${ }^{a} \tau_{\text {classical }}=\tau_{D D} \cdot a^{2} / 2.4 \rho_{D}^{2}$

${ }^{b} \mathrm{~L}=5 \mathrm{R}_{\mathrm{p}}$

C Split per Ref. $20\left(I_{T}=0.3745 I_{D}\right)$
} 


\title{
Appendix E: Conditions to Achieve Field Reversal by Neutral Injection
}

\author{
J. A. Byers
}

Our best working tool for analyzing the reversed-field mirror configuration is the SLPERLAYER code developed for the Astron program. Revised to simulate neutral infection, it is now being used to study buildup to fleld reversal in a mirror machlne and to determine properties of the steady state. The code now includes electron drag and charge exchange on the neutral beam, but as yet no angular scattering. The main function of the code is to calculate the selffield generated by the lons and the ion orbits in this field as a function of time. In the past, the code predicted reasonably well both the fallure to achieve field reversal by multiple injection of electrons in the LL.L Astron experiment and the success achleved at cornell by injecting a single, high-current pulse.

For the present purposes, the main defect of the code is the assumption of axisymetry (no quadrupole component). We believe this to be of limited Importance in determining the equilibrium configuration in the interior region where the closed-field pattern forms. However, imposing symmetry suppresses possible modes of instability that must then be examined efther analy:ically or numerically with other, more complex codes (see below). Also, is of this writing all runs have concantrated on the present 2XIIB parameters $\left(a / o_{1}: 2\right)$, but modifications to treat $a / b_{1}$ up $t, 10$ are in progress.

The code is limited in scope, allowing no electron currents or space-charge effects. Within these 11mtations, the code should be able to examine the $r, z$ equilibrium, including all effects of the mirrortearing mode and also the effects of another related electromagnetic mode with $k_{\perp}=0,21$ and including the full generality of five-phase space dimensions. One rather severe approximation is made: the relevant time scales, $\tau$, such as the drag tine or filling time, are shortened considerably, typically by factors of order of 100. The product I $\tau$ is kept consistent with the experiment, and an attempt is made to keep $\tau$ long compared to an axial bounce pertod.

The initial work indicated that fleld reversal was easily obtainable and persisted in steady state after initlal transients if the beams were arranged to form a coherent ring current. This injection prescription 
is actually unrealistic, and this pase yenr we have concentrated on simulating $2 x$ with realistic infection. currently, the code predicts that reversal is possible in the 2 XIIB experiment provided the beams are forused of axis: high $B$.

$$
R=\frac{\text { gnp }}{\text { Bve }_{\text {vac }}^{2}}>1 \text {. }
$$

Is obtainable regardless of the focusing. This condtion, however, is accompanted by a slow but steady axial loss of particles (this did not occur with ring-like injection). This loss is persistent but it is not yet known $1 \mathrm{f}$ it is caused by the physics (nonatiabatic containment?) or by numerical effects. Even if real, the loss raze is sufficiently slow that it thay not prevent buildup in a system with realistic time constants. That is, the loss rate is of the same order as the actual real time loss rate of hot particles due to electron drag $\left(T_{\mathrm{e}} \approx 100 \mathrm{eV}\right)$. For $2 X-1$ ike parameters, we have obtalned a strong reversal

$$
\left(\xi=\frac{\Delta \mathrm{B}}{B_{\text {vac }}} \approx 2\right)
$$

steady state for $I \approx 600 \mathrm{~A}$. This case used unfform injection over a length, $L_{\text {inf }}$, of $20 \mathrm{~cm}$ centered at the midplane, and over a radius $r_{0}=5 \mathrm{~cm}$, a drag coefficient appropriate to $\mathrm{T}_{\mathrm{e}}=100 \mathrm{eV}$, and
Included charge exchange on the beam. Allowing higher $T_{e}$ will lead to higher $F$ and $B$ for the same current or to marginal $\xi$ for lower currents.

A typlcal result is shown in Fig. F-1. The mirror ratio $R_{\text {vac }}$ over the occupied region is only 1.05; that is, the self-fleld alone confines the axtal preasure.

Shown in Fig. F-l are typical fleld lines $f i n$ an $r-z$ cross section Indicating a central core of closed rield lines. The flgure shows that the high-density region, defived as the region enclosed by the contour of half-peak density, is contained nearly entirely within the closed ines. This still leaves a sizable fraction of the total number of particles - perhaps half - outide the closed-line region, since for equal densities the amount of net mass is greater at a layer radius in the open-line region. The plasma has expanded radially to a radius $r=a$, somewhat beyond the injection radius $r_{0}$. Much of this contact with the open region is due to the large orbits,

$$
\frac{p_{i}}{r_{0}} \sim 1
$$

in this example. Smaller orbit systems may improve on this.

The plasma has also pinched in axtally to a mean length (full-width half-maximum) of : 


$$
\text { FWH }=\frac{\mathrm{L}_{\text {In } 1}}{4}=\mathbf{r}_{0^{\circ}}
$$

This is a typical result. Longer axial systems can occur if the infection region is extended. In one example, a steady state occurred for a FWH $=8 r_{0}$. longer systems are subject to breakup due to tearing modes. In essence, the system adjusts itself to a finite-length equilibrium with conditions necessary for prevention of any instabllity of the mirror-tearing mode type and of other related modes. The questions remaining are the modes lacking azimuthal symmetry $\left(e^{1 m \theta}, m \neq 0\right)$.

In progress are the following:

- Inclusion of classical

Coulomb scattering.

- Inclusion of $\mathrm{rf}$-induced velocity-space diffusion.

- Control of equilibrium state via cholce of injection length and vacuum magnetic fleld shape.
- Examination of small $\rho_{t} / a$ systems. Some reversed-fieid results have been obtained for $p_{1} / a=1 / 4$. In principle, there appears no obstacle to reversal for yet smaller $o_{i} / a$.

\section{- Examination of instabllity} mode involving $\theta$ perturbations. We are actively developing three-dimenstonal partic'ie codes that will start from a given steady state and examine the stabllity to $e^{i m \theta}$ modes, specifically the sausage and kink modes, considered to be the greatest danger, as discussed in Appendix $C$. These codes will enable us to examine stability without any restrictions on $p_{1} / a$.

We have experience with similar three-dimensional linear codes for the relativistic negative mass instability in Astron. 


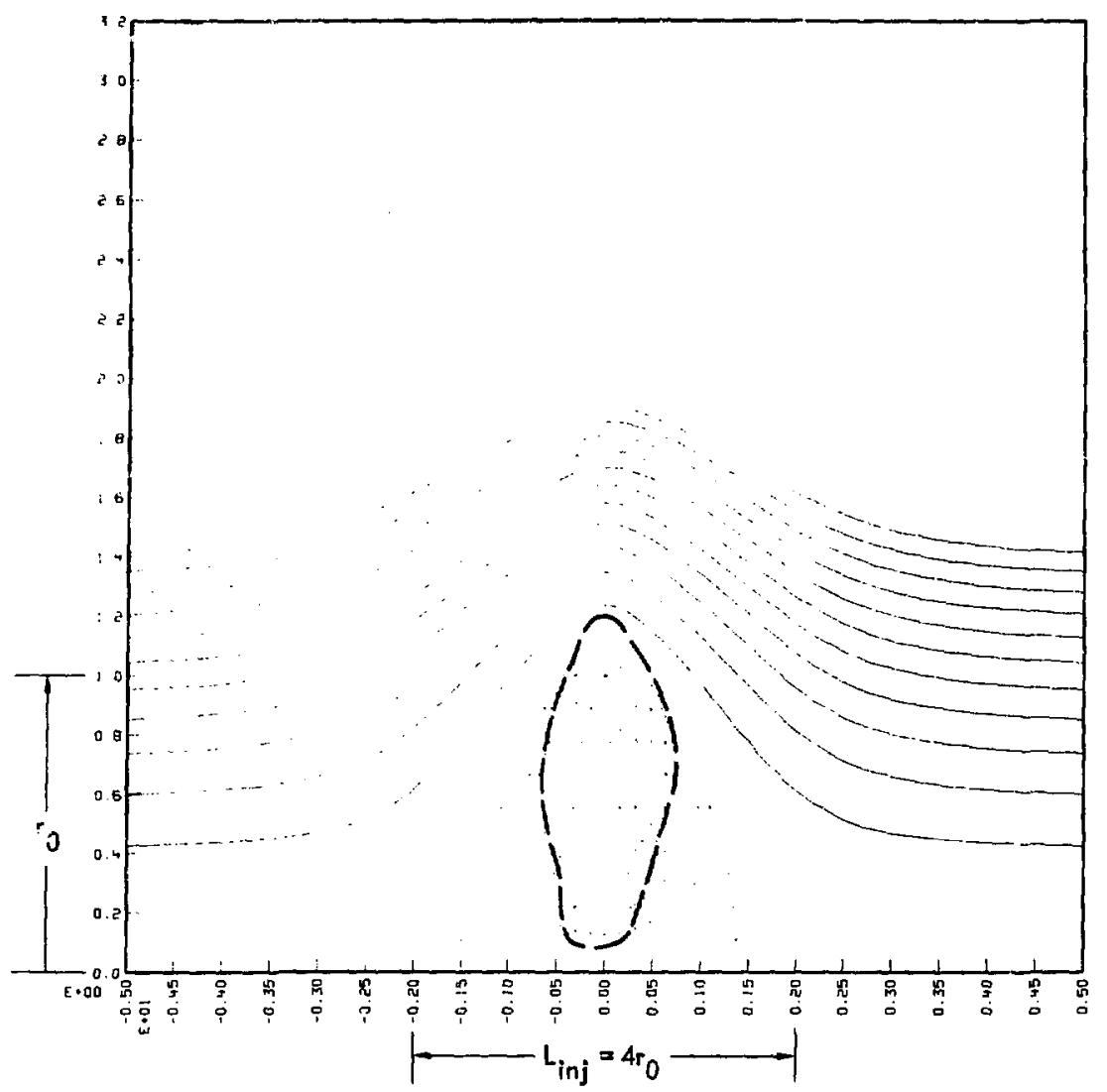

Fig. E-1. Field lines and half-peak density contour (dashed closed line) for a field-reversal example in an $r-z$ cross section. The density of iield lines does net indicate fleld strength due to the geometry. The closed field lines are shown as dotted curves. 


\section{Appendix F: Intense Ion Beams*}

J. W. Shearer and D. S. Prono

INTRODUCTION

Start-up plasmas for future mirror machines are likely to require several Coulotabs of lons in the 100-kev energy range. In addition, the achlevement of a reversed-field configuration by injection of energetic neutrals (or lons) will 11kely require a prompt injection of similar numbers of energetic particles. Although present ion-beam technology as developed at LLL/LBL provides sufficient beam current and energy to sustain mirror plasmas and/ar a field-reversing fon ring, the ability to initiate these conditions in appropriately short time scales is beyond present technology. The research we propose is designed to explore a new and unique means of generating intense, short-duration ion beams.

The method of intense ion-beam generation has evolved along the following lines. In 1973, experiments at Cornell University ${ }^{23}$ using pulsed electron-beam diodes demonstrated that electrons leaving the cathode and undergoing raflex-1ike wajectories through a transparent anode

*Abstracted 'rom Ref. 22. create an overabundance of electron charge density within the diode. If the anode becomes a source of lons, then space-charge neutrality within the diode is established by a modest ton flow from the anode. In 1974-75, experiments performed by Physics Interlationa ${ }^{24}$, Sandia Laboratories ${ }^{25}$, and LLL $^{26}$ demonstrated that if the overabundant electron charge density wthin the diode was not made uniform but rather peaked near the anode, then significant enhancement of ion flow intensity resulted.

It is important to understand t. ne fundamental differences between these intense ion sources and conventional ton sources. Both the conventional ion source and the pulsed, high intensity ion source have the basic property of a potential difference between parallel planes, one plane at ground and the other plane (the fon source plasma) at high potential. Mi is gives rise to the usual Childs-law ion current emission. The new zdidtional feature of the high intensity ton source is that electron emtision from the grounded plane is allowed. Net electron current flor in the external circuit is inht. sed by causing the electrons 
to reflex through the ion source

plane, and having these electron trajectorles collapse into the lon emission plane. The spatial distribution of electrons peaks near the ion emitter and increases the gradient of the potential there, resulting in Increased fon flow. That is, the electron cloud essentially neutralizes the Ion charge density throughout the gap, except for a narrow sheath near the ton emisston plane. The conceptual difference between the conventinnal ion source and the Intense fon source is schematically shown in Fig. $F-1$.

For completeness, we need to clarify that the conventional fon scurces are ineant for dc operation: thus, electron emission from the ground plane is to be prevented since this leads to breakdown. In the intense iun source, the pulse duration is 1 imited to the time scale for the - plasma flow from the two emitters (one of electrons and the other of lons) to driit across the gap at a thermal speed and short out the accelerating potential.

In this new apprcich to Ion-beam generation, the intensity and time scale of the fon beam are dependent upon the nature of the electron emission. Very intense but short duration ton beams (several $\mathrm{kA} / \mathrm{cm}^{2}$ for $100 \mathrm{~ns}$ ) require the very higin electron emission of a relativistic electron beam generator. Thus far, intense ion beams have been experimentally produced only in this manner. However, the basic concept should be applicable to somewhat longer durations (mlcroseconds) and lower currents (hundreds of $\mathrm{A} / \mathrm{cm}^{2}$ ) by appropriate modifications of the rechniques for producing the ion and electron emisston. This would match into a technology of fast capactors rather than high voltage Marx-charged Blumleins, greatly increasing the practicality of the concept for CTR applications.

\section{CORRELATION WITH OTHFR PROJECTS}

This work is closely related to the iarge neutral beam research and deveiupinent effort in piogress at LLL and LBL. It can be viewed as an extension of that effort into the regime of much higher current density for a short burst. The 100-keV ion energy range is still sufficiently low for efflclent conversion into a neutral beam by charge exchange.

TECHNICAL PROGRESS IN FISCAL YEAR 1976

\section{Exploratory experiments were} carried out using 2 weeks of rented time on the oWL-2 relativistic electron beam machine at Physics International. Preparations for 
the experiments involved prior

development and Fabrication at

Livermore of deuterium-loaded anode

folls and cathode plates, as well as the construction of mechanical hardware to attach the experiment to the OWL-2 generator, the fabrication of Faraday cups, and the calibration of silver-foll-activation neutron detertors. In addition, extensive use was made of previously calibrated voltage and current diagnostics on the OWL-2 machine.

Direct detection of fon currents was accomplished in these experiments, desp:-e the negative polarity of the olll-2 voltage. Faraday collectors were mounted inside the cathode, and their signals were brought out to the scopes through a speclally installed transit-time 1solator. The Faraday collector signals correspond to peak ion current densities in excess of $1 \mathrm{kA} / \mathrm{cm}^{2}$. In a few experiments, both the anode foil and the cathode foll were loaded with deuterium lons. In these cases, the callbrated neutron detectors recorded $10^{7}$ to $10^{8}$ neutrons per shot. When these data are combined with diode voltage measurements, thick-target yield calculations also correspond to average lon current densities of the order of $1 \mathrm{kA} / \mathrm{cm}^{2}$ or greater. Thus, the initial exploracory experiments established the existence of large pulsed ion currents in the 100-keV energy range and verified the concept of intense ion beam generation.

PROJECT GOALS FOR FISCAL YEAR 1977

Our goal is the design and fabrication of an intense ion beam system based on fast capacitor banks. Such a system will replace the highvoltage Marx-charged Blumleins used for experiments in $M 1976$ and will be more practical for CTR application. With this syotem, we aim to achieve a 100-keV ion beam of current density $1 \mathrm{kA} / \mathrm{cm}^{2}$ and $1 \mathrm{~ms}$ pulse duration. The $100-\mathrm{keV}$ energy $11 \mathrm{mitat}$ ion is dictated by the most advantageous infection scheme of neutralizing the beam before penetration into the mirror (for energles exceeding 100 $\mathrm{keV}$, the neutralization efficlency falls rapldly). Our second major goal is to optimize beam emittance.

PROPOSED RESEARCH FOR FISCAL YEAR 1977

Considerable research effort must be devoted to the creation of the two emitting plasmas required by the intense ion source concept. Once this hurdle is passed, research will be directed toward extraction of Ion beams and optimization of beam intensity and emittance. Paralleling this effort, we will initiate computational effort. The primary charter of computation wili be to furnish 
guidance in source optimization, to model the transient behaviour of th plasma emitting surfaces as they close on one another, and to addres the beam emittance question.

PROJECT GOALS FOR FISCAL YEAR 1978

The project goal of this year w111 be the demonstration that this new concept of intense ion sources can supply the necessary Coulombs at the $100 \mathrm{keV}$ required for mirror start-up and possibly fleld reversal.
PROPOSED RESEARCH FOR FISCAL YEAR 1978

Assuming reasonable success in previous research, we foresee that half of this year's effort will be directed toward optimizi.iig the intense ion beam divergence. Imbodied in this research will be studies on fleld shaping and contourang the emitting plasma surfaces. For the second half year, we will couple by way of a beam transport system a charge-exchange neutralizer and the grounded-plasma emitter of the Ion source. Experiments on this total system will furnish size-scaling laws needed to establish our goal.

\section{CONVENTIONAL ION SOURCE}

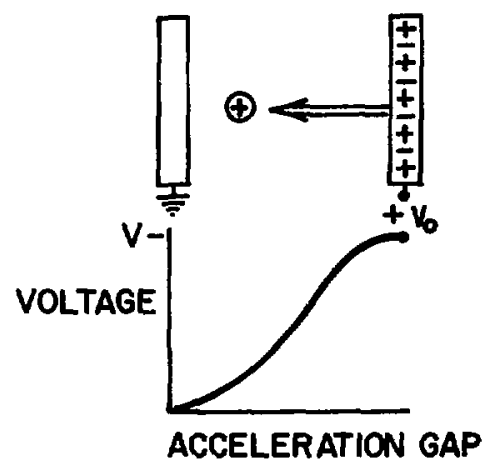

INTENSE ION SOURCE

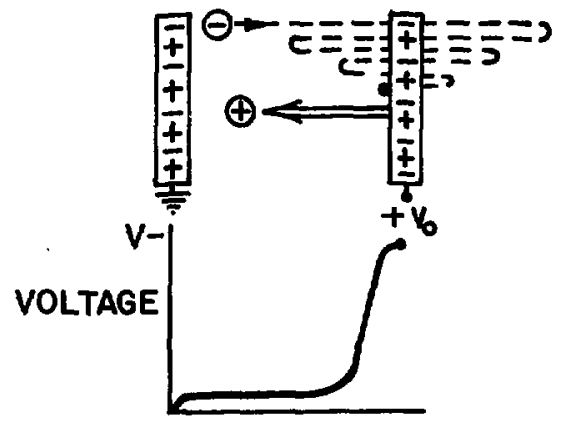

ACCELERATION GAP

Fig. F-1. Conventional ion source vs intense fon source. 


\title{
Appendix G: 2XC Magnet Set*
}

\author{
F. H. Coensgen
}

INTRODUCTION

Beyond demonstration in 2XIIB of bastc scaling laws for plasma tn open magnetic geometry is the question of optimum magnet design for either reactors o: FERF's utilizing open magnetic geometry. Thus, following the 2XIIB program we propose that optimization experiments be carried out in the $2 \mathrm{X}$ area. To avold unnecessary delays in acquisition of Information, we plan to fabricate in FY1977 a new magnet set (2XC, FIg. G-1) and high-vacuum chamber for the first such experiment. $2 \times \mathrm{C}$ will be installed during the first part of FY1978. Operation of 2XC will begin later in FY1978. Major elements of the 2XIIB system such as the intense neutral beams, the diagnostics, the data acquisition systems, the machine controls, and a large part of the $2 X I I B$ vacuum system will be utflized in the $2 \times c$ experiment.

Among the magnetic field variations considered in reactor and FERF designs those most frequently discussed are use of $\int \frac{\mathrm{d} 1}{\mathrm{~B}}$ stabllity

*Abstracted from Ref. 27. rather than absolute min-B stability, multiple mirrors, and large mirror ratios ( $R>3$ ). Prtilmtnary design of a magnet set which provides for a continuum of magnetic field geometrles from those which are minimum$B$ stable through progresstvely weaker $\int \frac{\mathrm{d} l}{\mathrm{~B}}$ stable fields to an unstable simple-mirror configuration. Only modest modification of the existing capacitor bank is required for operation of the $\int \frac{\mathrm{d} 1}{\mathrm{~B}}$ system near the $0.9 \mathrm{~T}$ central field and $\mathrm{R} \approx 2$ of the present $2 X I I B$ experiments.

With the proposed Increased energy storage included herein, mirror ratios of 3 could be achfeved in an $\int \frac{\mathrm{d} l}{\mathrm{~B}}$ stable fleld. Large mirror ratios are common to all reactor designs, and Investigation of the predicted advantages is of prime importance. These advantages are the following:

- Reduced collisional loss through reduction of the lass cone angle and the effect of the ambipolar potential.

- Iricreased beta threshold for the "mirror instability". The reaction rate per unit volume and hence the power density increases with $\beta$. 
- Reduced departure of the ion velocity function from Maxwellian; thus, reduced saturation level, and hence lower loss rates for residual instabllities.

High $\beta$ is predicted to increase the effective mirror ratio and hence further reduce co.lisional loss, bringing the lon velocity function closer to Naxwellian. Numerical Fokker-Planck computations indicate that higher betas can be sustained if the neutral beams are injected close to the loss cone rather than perpendicular to the magnetic field lines. Thus, the new magnet will provide the oblique injection of neutral beams.

Although the energy limit for adiabatic particle containment in the vacuum magnetic field seems assured, adiabaticity at high- $\beta$ values is uncertain. Test of the theoretically predicted limit in the presence of dense energetic plasmas is an important goal of the $2 \mathrm{Xc}$ experiment.

The option of simple-mirror geometry in $2 x C$ will provide the opportunity to experimentally reexamine MHD stabilization by line tying. Use of the extensive, sophisticated, 2XIIB diagnostic capability will for the first time allow a quantitative determination of the minimum heat drain associated with line tying.

\section{CORRELATION WITH OTHER PROJECTS}

This project, as the $2 X I I B$ project, is dependent upon the development of reliable, high-current, high-energy, neutral beams being developed in the LLL/LBL Neutral Bean Program.

Plasma target and transition to a neutral beam sustained plasma will follow the methods currently under development in $2 X I I B$.

PROGRESS IN THE PRIOR FISCAL YEAR (FY 1976)

\section{Alternative magnet designs} including dc magnet sets and power supplies, comblned YIn-Yang and circular magnets, and high-mirrorratio, pulsed Yin-Yang systems have been considered. At present, these designs have been rejected in favor of a pulsed Yin-Yang set combined with pulsed "cee"-shaped magnets beyond the Yin-Yang mirrors. The four-coil set provides for minimum-B or $\int \frac{\mathrm{d} l}{\mathrm{~B}}$ stable systems and for $a$ rather modest investment in energy storage a high ( $R$ of at least 3 ) mirror ratio experiment.

Analysis has shown that the theoretical threshold for the "mirror instability" is a function of mirror ratio, $R$. Detailed numerical analysis Indicates that the $\beta$ limit is a function of angle of injection as well as the mirror ratio. Experimental 
confirmation of the predicted increase of $B$ with mirror ratio and oblique injection is needed.

PROJECTED GOALS FOR THE C.URRENT FISCAL YEAR (FY 1977)

The following goals are projected for FY 1977.

- Preparation for winding and vacuum impregnation will proceed concurrently with detalled engineering design during the first quarter of FY 1977. Actual magnet construction will begin about December 1976. Lay up of the glass-reinforced magnet support structure will begin in April 1977. By October 1977, the new magnet should be ready for installation.

- The $2 \times c$ magnet set may be as much as a metre longer than the $2 \mathrm{XIIB}$ set. This may increase the overall weight beyond the 435 crane capacity and may necessitate changes in the construction procedure. These changes (which would require considerable insite construction) would prolong the "down time" between 2XIIB and 2 XC.

Fabrication and construction techniques will be the same as those used for $2 X I I B$, thus no engineering or materials test programs will be needed. The construction uncertainty is the cost and avallability of petroleum based resins and glass-fiber reinforcement.

PROPOSAL FOR RESEARCH IN THE BUDGET YEAR (FY 1978)

Approximately 6 months w111 be required to replace $2 X I I B$ with $2 X C$. Following Installation, approximately 3 months will be required to reestablish vacuum conditions, neutral beam operation, and diagnostic capability. Thus, comparison of plasma containment of line-tied $\int \frac{\mathrm{dl}}{\mathrm{B}}$ and minimum-B stable configurations should begin in the last quarter of FY 1978 and continue through FY 1979. The capacitor bank will also be upgraded during the first half of FY 1978. 


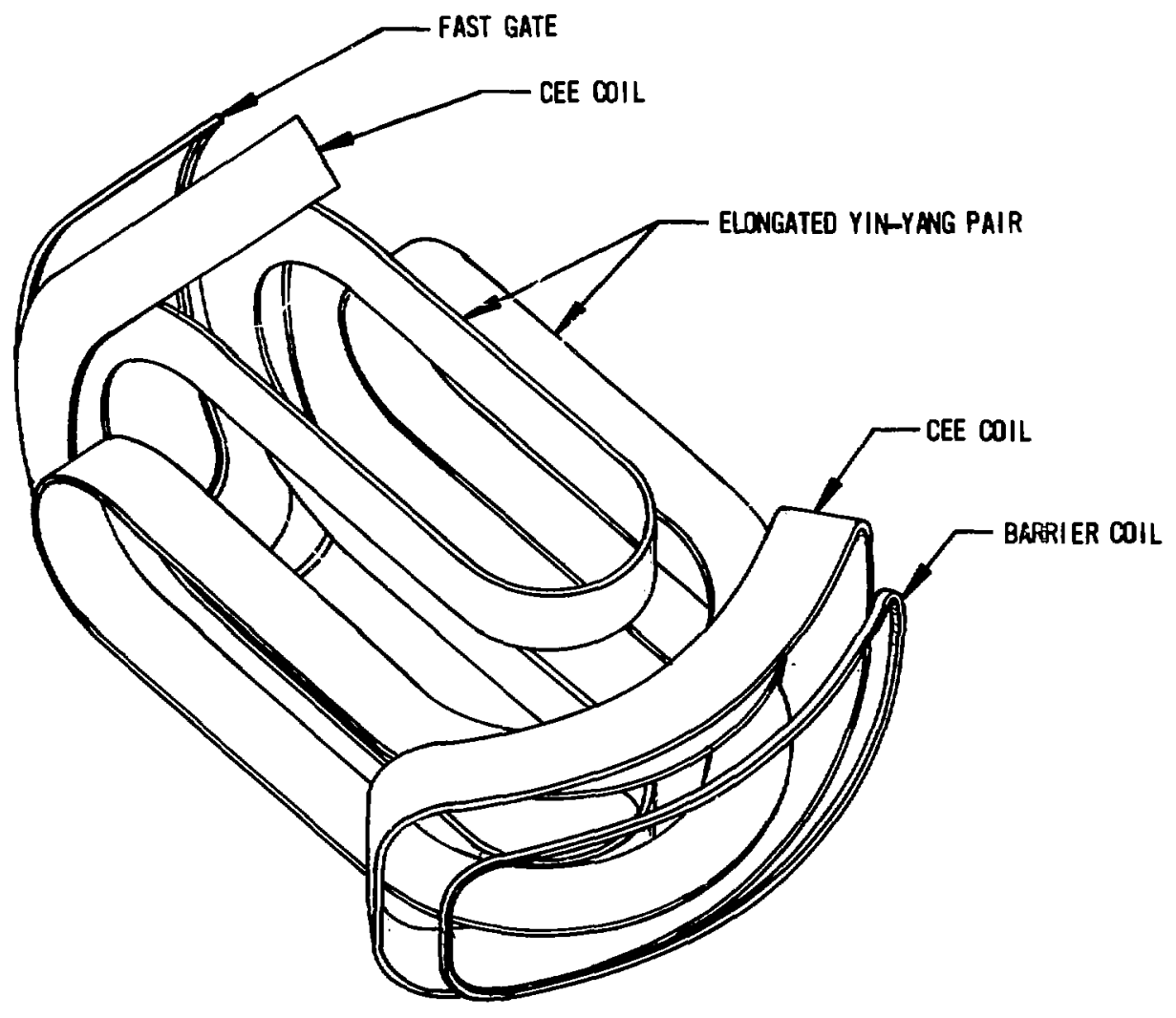

Fig. G-1. The 2XII magnet set. 


\title{
Appendix H: Operating Modes and Trade-Offs for Mirror-Torus Reactors
}

\author{
W. C. Condit
}

\section{INTRODUCTION}

The combination of a toroidal return link and a mirror reactor cell (or cells) has been proposed as a possible steady-state high-beta fusion reactor. $11,28,29$ Broadly speaking, such reactors can run in one of two modes: two component or conventional. The first is usually thought of as having the tritium density much higher than the deuterium density, whereas $n_{T}=n_{D}$ for the second. It is the purpose of this appendix to show that the need to minimize the required $n \tau$ in the toroldal link drives one to choose approximately equal tritium and deuterium densties. Thus $1 t$ appears that there is no twocomponent torotdally linked system which is optimal for a reactor: the 2-component mode merges into the conventional 1-component mode. The only feature of the two-component idea that is clearly retained is the Idea of having the tritium temperature well below the deuterium temperature. The possibility of this is implictt in the toroldally-1inked mirror proposal of Watson and Cordey, 11,28 which has a peak in the particlecontainment time at energies well below the infection energy. Thus, any mirror-torus hybrid is apt to be similar to that of Watson and Cordey. We will examine a series of reactor designs leading to thelr design as the optimum. We will assume (arbitrarily) a central field of $\mathrm{B}_{0}=2.0 \mathrm{~T}$, realizing that this can be scaled up.

ENERGY BALANCE FOR 2-COMPONENT SINGLE-CELL MODEL

The two-component model is taken to be one In which deuterium lons are injected with $\mathrm{E}_{0} \geq 10 \mathrm{~T}_{e}$ into a background tritium plasma with density $\mathrm{n}_{\mathrm{T}} \gg \mathrm{n}_{\mathrm{D}}$. They acquile an average energy, $E_{a v}$, before being lost. The deuterlum scattering losses from the mirror and energy loss to the tritons are neglected relative to $D-e$ drag ( $\tau_{\text {dem }}$ ) In the first approximation. The plasma in the torus is assumed to be a pure tritium plasma - deuterons are taken as lost immediately after leaving the mirror. Tritons and electrons leave the torus at a rate $n_{T} / \tau_{T T}$ per unit volume. Let the tritium temperature $\mathrm{T}_{\mathrm{T}}$ equal the electron temperature $T_{e}$. Let $V_{T}, V_{m}$ be the torotdal and mirror plasma 
volumes, and assume the tritium density is the same in the torus and the mirror. Then the condition that the power injected into the mirror be able to sustain the toroldal losses is

$3 n_{T} T_{e} V_{T} \tau_{T T}-1=n_{D} E_{a v} V_{m} \tau_{d e m}^{-1}$

We will now make an estlmate of the volume ratio, and solve Eq. (H1) for $n_{T} T_{T T}$. It is hard to make a toroldal return with radius less than the distance between field maxima in the mirror, which is typically about four times the effective length of the mirror plasma. 20 since the crosssectional areas of the plasma in the torus is assumed to be down by the mirror ratio, $R$, from that in the mirror, the volumes are related (for a single mirror cell) by

$$
\mathrm{V}_{\mathrm{T}} / \mathrm{V}_{\mathrm{M}}=8 \pi / \mathrm{R}
$$

To reduce the $n \tau$ requirements as much as possible, we assume a total mirror ratio of 6 , coming, for instance, from $R_{v a c}=2.68, \beta=0.8$. Combining Eqs. (H1) and (H2) and solving for $n_{T} \tau_{T}$, we get a winimum reasonable toroldal (nT):

$$
n_{T} T_{T T}=\left[\frac{4 \pi}{E_{e}}\right] \frac{n_{T}^{2}\left(n_{e} \tau_{d e m}\right)}{n_{D}\left(n_{D}+n_{T}\right)}
$$

Thus, we see that any restriction of the form of Eq. (H2), ultimately imposed by engineering considerations, results in a minimum toroidal nt whtch is a product of a density dependent factor, an energy-dependent factor given within narrow limits by $Q$ considerations (see below), and the basic nt for deuterons slowing down on electrons. It is sbvious that one wants to drop $n_{T}$ and raise $n_{D}$ to ease the $n T$ requirements; this leads one out of the 2-component regime. As an example of the stringent requirements placed on the torus by the conditions of Egs. (H1) and (H2), consider the case $n_{D}=0.33 n_{T}$, $\mathrm{T}_{\mathrm{e}}=16 \mathrm{kev}, \mathrm{E}_{0}=200 \mathrm{kev}, \mathrm{E}_{\mathrm{av}}=$ $120 \mathrm{keV}$. The toroidal component using Eq. (H3), must have an nt of $2.7 \times 10^{14} \mathrm{~s} / \mathrm{cm}^{3}$. If a torus of this quality could be built, it would be better to run it as a thermal reactor with $\mathrm{n}_{\mathrm{D}} \stackrel{\sim}{=} \mathrm{n}_{\mathrm{T}}$ : using the bare Lawsen criterion at $16 \mathrm{keV}$ ( $n t \doteq 2.5 \times 10^{13}$ at $Q=1$ ), a thermal reactor would have $Q \geq 10$ while the 2-component reactor would only have $Q=3$ at the same temperature with $n_{\tau} \gg n_{D}$, At $8 \mathrm{kel}$, the nt requirements are somewhat reduced, as shown for the onecell case in Table $\mathrm{H}-\mathrm{l}$. However, $\mathrm{Q}$ is also reduced (to about 2), and the reactor parameters are not attractive. For this reason, we examine multiplecell designs to investigate 
improvements in the torus/mirror volume ratio given by $\mathrm{Eq}$. (H2).

\section{MULTIPLE-CELL 2-CONPONENT DESIGNS}

A possible two-component, sixcell mirror layout is shown in Fig. H-1. The floor-plan shape of an individual mirror cell has been found In previous studies to be the projection of a cone plus a hemisphere of radius $L$, where $L$ is the distance between mirrors. 20,30 since blanket and magnet-shielding requirements set a lower limit of about $\mathrm{L}=10 \mathrm{~m}$, the overall layout is rather large and is fixed by the individual cell shape and the number of cells. So far, I have not provided a location for the direct converters. If we assume that these can be worked in at diverters placed near the corners, we note that $v_{\text {cell }}=0.25 \pi R_{p}^{2} L$, and $f$ ind

$$
\begin{aligned}
v_{\text {torus }} & =v_{\text {cell }}(72 / R) \\
& =V_{M}(12 / R) .
\end{aligned}
$$

An alternative eight-cell layout due to Watson and Cordey is shown in Fig. H-2. Here we find

$$
\begin{aligned}
v_{\text {torus }} & =v_{\text {cel1 }}(77.25 / R) \\
& =v_{M}(9.65 / R)
\end{aligned}
$$

A similar relationship will hold for any number of cells, with the limiting value of $v_{\text {torus }}=(8 / R) v_{M}$ for a large number of cells, since the effective plasma length is $1 / 8$ of the reactor cell diameter. The case in Eq. (H5) is already quite close to this limit, and is well worked out, 11 so we choose it as our reference design. Parameters for $Q=2$ are given in Tables $\mathrm{H}-1$ and $\mathrm{H}-2$ with the assumption that $n_{T}=3 n_{D}$. The $n t$ requirement for the multiple-cell reactor is reduced over a factor of 2 from the single-cell case.

ESTIMATES FOR TWO-TEMPERATURE WATSON-CORDEY REACTOR

If we set $n_{D} \equiv n_{T}$, but allow the deuterium and tritium temperatures to be different, we can estimate the performance of an eight-cell reactor by neglecting the reactions of the therma 1 component, assuming all reactions occur between trapped deuterons and cool tritons, and again neglecting mirror scattering losses. We will use the same value of $\overline{\sigma v}$ for a $200-\mathrm{keV}$ injection as used above for $n_{T}>n_{D}$, reallzing that a more complete reactor design would require a Fokker-Planck calculation modified to take into account the energy dependence of the cold-component loss rate from the torus. 29 The results are shown in 
Tables $\mathrm{H}-3$ and $\mathrm{H}-4$ : one can see that $n_{T} \tau_{T T}=4 \times 10^{12}$ may lead to a viable reactor, and $n_{T} \tau_{T T}=$ $2 \times 10^{13}$ looks very interesting. According to Ref. 29, the actual reactor $Q$ 's may be enhanced considerably over those shown. (For Instance, thermal reactions in the toroldal section will help.) Thus the apparent drop in "Estimated $Q$ " from the first two tables should not be considered as significant.

\section{CONCLUSIONS}

Two-component toroidal return links, with $n_{T} \gg n_{D}$, appear to require such high values of $n t$ for the toroldal component as to be practically in the regime for a purely toroidal reactor. A twotemperature version of the scheme proposed by Watson and Cordey 11 appears, however, to allow interesting reactors to be built with significantly reduced values of $n T$. This would seem to be the logical direction for research on mirror-torus hybrids to proceed. The key remalning question is whether the required $n T^{\prime} s$ can be achleved in a nonaxisymmetric system in the face of possible microinstabilities. A related question is whether the hot Ions can be contalned in the torus to any appreciable extent - we have not assumed this, in computing fusion yield, but it may allow us some increased outpuc, perhaps by increasing $\mathrm{L}_{\text {eff }}$.

The power outputs shown in Tables $\mathrm{H}-1$ through $\mathrm{H}-4$ are disappointingly small, and a subsequent report w11l discuss higher outputs at larger magnetic field values. 


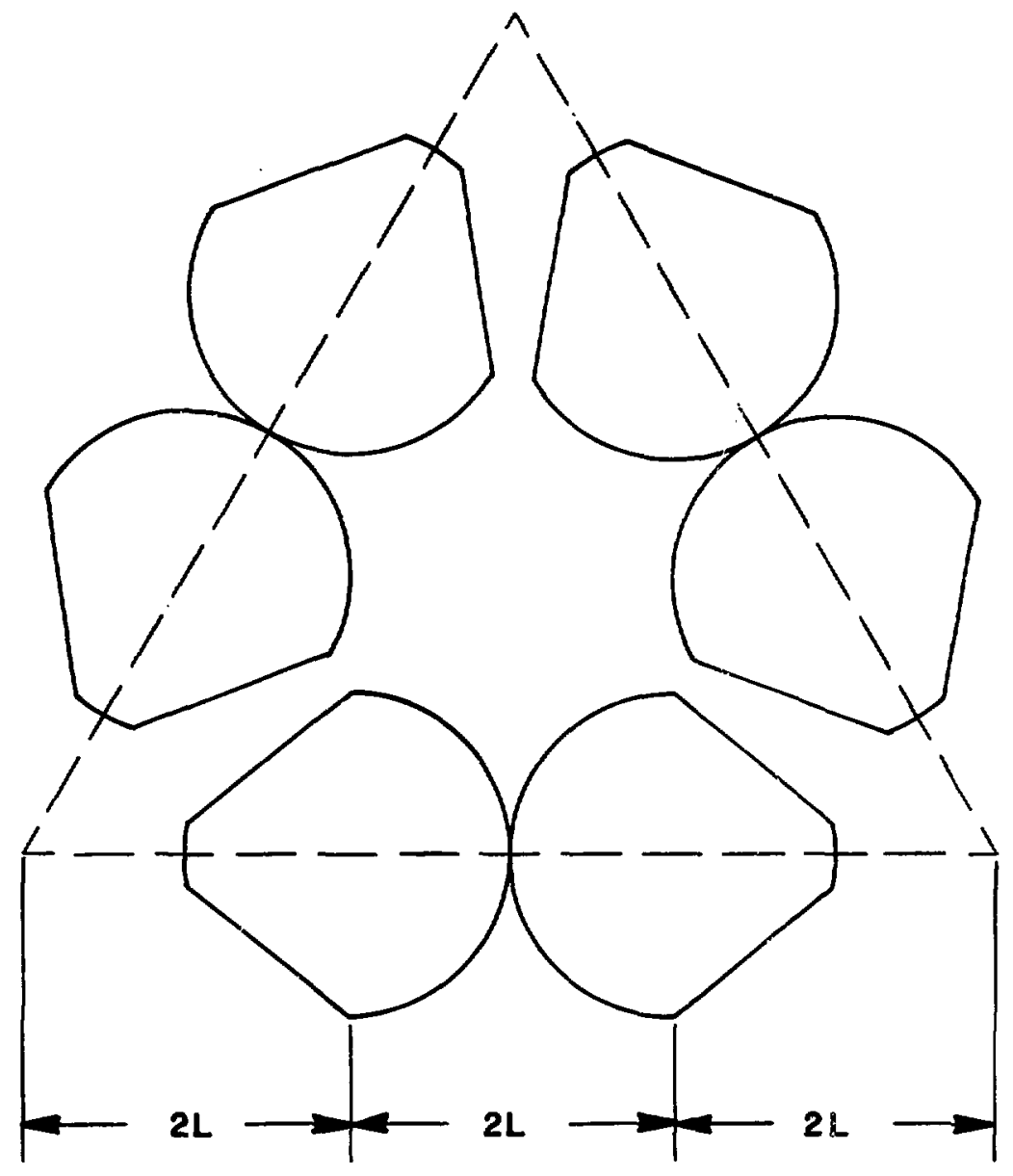

Fig. H-l. Plan view of six-cell, linked-airror reactor. Distance between throats is $\mathrm{L}$. 


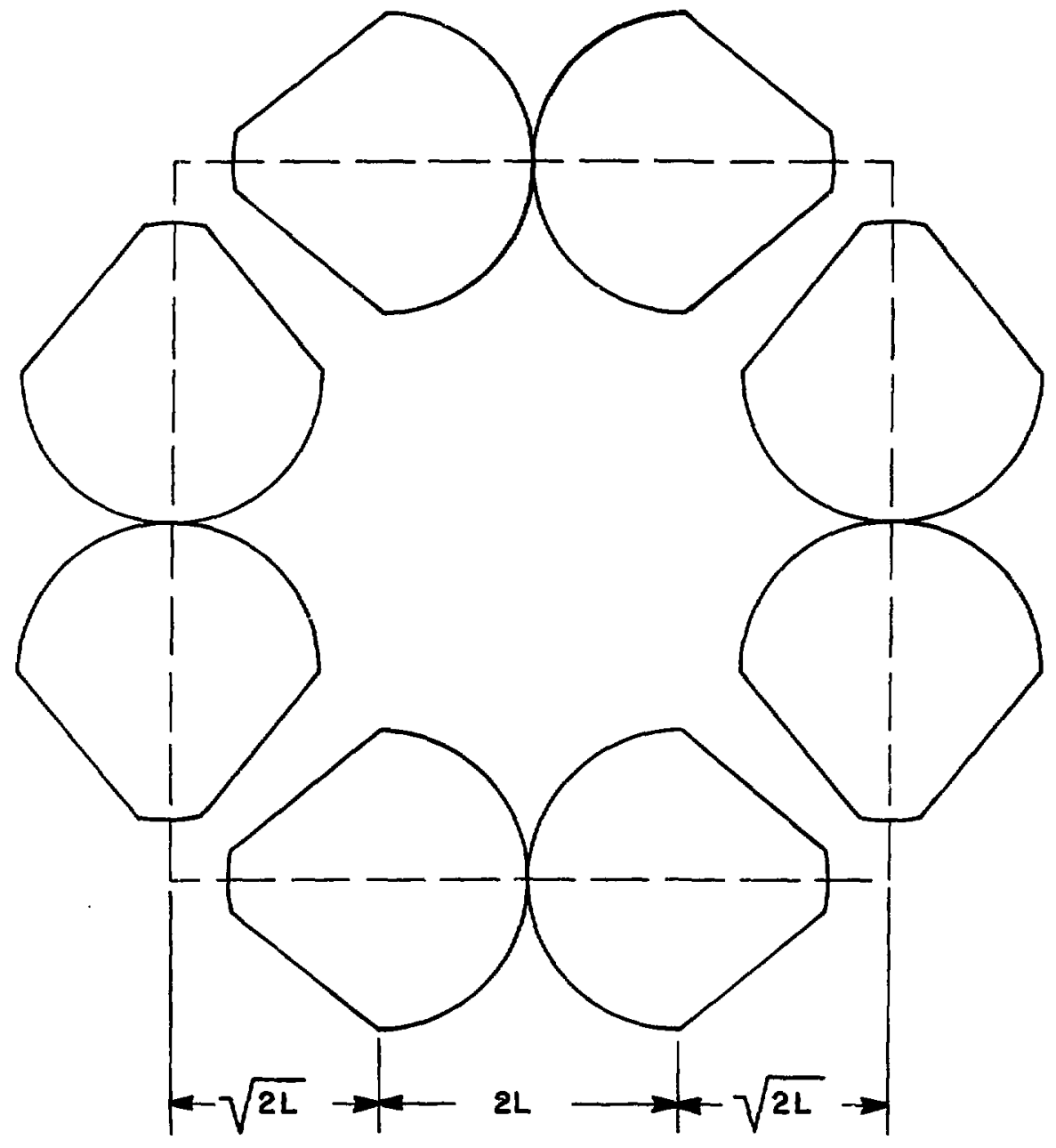

Fig. H-2. Plan view of eight-cell linked-mirror reactor-....Distance between throats is $\mathrm{L}$. 
Table H-1. Two-Component Reactor for $Q=2$.

\begin{tabular}{|c|c|}
\hline$E_{\mathrm{DO}}=200 \mathrm{kV}$ & $\tau_{\text {dem }}=0.1195 \mathrm{~s}$ \\
\hline$B_{0}=2.0$ (vacuun.) $T$ & Plasma radius ${ }^{a}=47 \mathrm{~cm}$ \\
\hline$B_{\text {throat }}=5.36$ vacuum) $\mathrm{T}$ & Wall radlus ${ }^{b}=112 \mathrm{~cm}$ \\
\hline Mirror Ratio $\approx 6$ (total) & Major radius $=703 \mathrm{~cm}$ \\
\hline$B=0.8$ & Fusion density $=28 \mathrm{~W} / \mathrm{cm}^{3}$ \\
\hline$T_{D}=73 \mathrm{kV}$ & Input density $=7.74$ (deuterons) $\mathrm{W} / \mathrm{cm}^{3}$ \\
\hline$T_{e}=8\left(T_{e}=T_{T}\right) k V$ & Estimated $Q=3.64$ \\
\hline$n_{D}=0.52 \times 10^{1<} \mathrm{D} / \mathrm{cm}^{3}$ & Llat:1ng $Q^{c}=2.1$ \\
\hline$n_{T}=1.57 \times 10^{14} \mathrm{~T} / \mathrm{cm}^{3}$ & 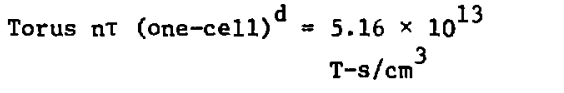 \\
\hline $\ln \Lambda=18$ & Fuston power $=35 \mathrm{MW}$ [at $17.7 \mathrm{MeV} /$ fusion] \\
\hline
\end{tabular}

a Infection requires $\mathrm{nR}_{\mathrm{p}}=10^{16}$.

b Wall flux $=1 i^{14} \mathrm{n} / \mathrm{cm}^{2} \mathrm{~s}$.

c From Ref. 30. Discrepancies are due to $\overline{\sigma v}$ varlation in estimate and to neglect of energy transfer to tritium.

d From Eq. (H3) - for comparison only. 
Table H-2. Two-component reactor: $Q=2(8$ cells $)$.

$$
\begin{aligned}
& E_{D O}=200 \mathrm{kV} \\
& B_{0}=2.0 \mathrm{~T} \\
& T_{e}=8 \mathrm{kV} \\
& \mathrm{n}_{D}=0.52 \times 10^{14} \mathrm{D} / \mathrm{cm}^{3} \\
& \mathrm{n}_{\mathrm{T}}=1.57 \times 10^{14} \mathrm{~T} / \mathrm{cm}^{3}
\end{aligned}
$$

(Other plasma parameters per Table $\mathrm{H}-1$. )

$$
\begin{aligned}
& \text { Wall radius }=112 \mathrm{~cm} \\
& \mathrm{P}_{F}^{\prime}=20 \mathrm{MN} \text { (fusion) } / \mathrm{m} \\
& \mathrm{L}_{\text {cell }}=7.03 \mathrm{~m} \\
& \mathrm{~L}_{\text {eff }}=1.76 \mathrm{~m} \\
& \mathrm{P}_{F}=281 \mathrm{MW} \text { (at } 17.7 \mathrm{MeV} / \mathrm{fusion} \text { ) } \\
& \text { Torus } \mathrm{n} \tau=1.98^{*} 10^{13} \mathrm{~T}-\mathrm{s} / \mathrm{cm}^{3}
\end{aligned}
$$


Table $H-3$. One-component reactor for $Q=2$ (eight cells)

\begin{tabular}{|c|c|}
\hline$E_{D O}=200 \mathrm{kV}$ & $\tau_{\text {dem }}=0.188 \mathrm{~s}$ \\
\hline$B_{0}=2.0$ (vacuum) $T$ & Plasma radius ${ }^{a}=74.9 \mathrm{~cm}$ \\
\hline$B_{\text {throat }}=5.36$ (vacutum) $T$ & Wall rad1us ${ }^{b}=150 \mathrm{~cm}$ \\
\hline Mirror ratio $=G$ (tota $)$ & Major radius $=937 \mathrm{~cm}$ \\
\hline$\beta=0.8$ & Fusion density $-15 \mathrm{~W} / \mathrm{cm}^{3}$ \\
\hline$E_{D A V}=110 \mathrm{kV}$ & Input density $=6.22 \mathrm{~W} / \mathrm{cm}^{3}$ \\
\hline$T_{e}=8\left(T_{e}=T_{T}\right) k V$ & Estimated $Q=2.42$ \\
\hline $\mathrm{n}_{\mathrm{D}}=6.6 \times 10^{13} \mathrm{D} / \mathrm{cm}^{3}$ & Limiting $Q^{c}=2.1$ \\
\hline $\mathrm{n}_{\mathrm{T}}=6.6 \times 10^{13} \mathrm{~T} / \mathrm{cm}^{3}$ & Torus nt $=4.40 \times 10^{12} \mathrm{~T}-\mathrm{s} / \mathrm{cm}^{3}$ \\
\hline$\overline{\sigma v}=12 \times 10^{-16} \mathrm{~cm}^{3} / \mathrm{s}$ & 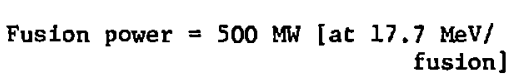 \\
\hline
\end{tabular}
a Injection requires $\mathrm{nR}_{\mathrm{p}}=10^{16}$.
b Wall flux $=10^{14} \mathrm{n} / \mathrm{cm}^{2} \mathrm{~s}$.
C From Ref. 30. Discrepancies are due to $\overline{\sigma v}$ variation in estimate. Neglects burn of cool component.


Table H-4. One-component reactor for $Q=3$ (eight cells).

$$
\begin{aligned}
& E_{D O}=200 \mathrm{kV} \quad \tau_{\text {dem }}=0.67 \mathrm{~s} \\
& B_{0}=2.0 \text { (vacuum) } T \quad \text { Plasma radius }{ }^{a}=95 \mathrm{~cm} \\
& B_{\text {throat }}=5.36 \text { (vacuum) } \mathrm{T} \quad \text { Wall } \text { radius }^{\mathrm{b}}=150 \mathrm{~cm} \\
& \text { Mirror ratio }=6(\text { tota } 1) \quad \text { Major radius }=937 \mathrm{~cm} \\
& \beta=0.8 \quad \text { Fusion density }=9.3 \mathrm{~W} / \mathrm{cm}^{3} \\
& \mathrm{E}_{\mathrm{DAV}}=120 \mathrm{kV} \quad \text { Input density }=1.48 \text { (deuterons) } \mathrm{W} / \mathrm{cm}^{3} \\
& T_{e}=16\left(T_{T}=T_{e}\right) k V \quad \text { Estimated } Q=6.29 \\
& n_{D}=5.2 \times 10^{13} \mathrm{D} / \mathrm{cm}^{3} \quad \text { Limiting } Q^{C}=3.0 \\
& \mathrm{n}_{\mathrm{T}}=5.2 \times 10^{13} \mathrm{~T} / \mathrm{cm}^{3} \quad \text { Torus } \mathrm{nT}=2.28^{*} 10^{13} \mathrm{~T}-\mathrm{s} / \mathrm{cm}^{3} \\
& \overline{\sigma V}=12 * 10^{-16} \mathrm{~cm}^{3} / \mathrm{s} \quad \text { Fusion power }=500 \mathrm{MW}[\text { at } 17.7 \mathrm{MeV} / \\
& \text { fusion] } \\
& \ln \Lambda=18
\end{aligned}
$$

\footnotetext{
a Injection requires $n R_{p}=10^{16}$.

b Wall flux $=10^{14} \mathrm{n} / \mathrm{cm}^{2} \mathrm{~s}$.

c From Ref. 30. Discrepancies are due to $\overline{\sigma v}$ variation in estimate. Neglects burn of cool component.
} 


\section{References}

1. F. H. Coensgen and T. K. Fowler, LLL Mirror Program Presentation to the Fusion Power Coordinating Committee, Lawrence Livermore Laboratory (January I976).

2. 0. A. Anderson, et al., "Plasma Production and Confinement in the Baseball II Mirror Experiment," in Proc. Fifth Conf. Plasma Physics and Controlled Nuclear Fusion Research, Tokyo, 1974 (IAEA, 1975) Vol, I, p. 379.

3. G. A. Carlson and R. W. Moir, "Mirror Fusion Reactor Study," in Pros. American Nuclear Society Winter Meeting, San Francisco, 1975 (ANS, in preparation); also Lawrence Livermore Laboratory Rept. UCRL-76985.

4. M. E. Rensink, et al., "Theoretical Studies of Plasma Confinement in Magnetic Mirrors," in Proc. Fifth Conf. Plasma Physics and Controlled Nuclear Fusion Research, Tokyo, 1974 (IAEA, 1975) Vo1. I, p. 311.

5. J. Busnardo-Neto, J. Dawson, T. Kamimura, and A. T. Lin, Phys. Rev. Lett. 35, 162 (1975).

6. S. H. Humphrtes, Plasma Phys. 17, 973 (1975).

7. R. V. Lovelace, Phys. Rev. Lett. 35, 162 (1975).

8. A. G. Eskov, et a1., "Plasma Conflnement in a Pulsed System with a Compact Toroidal Configuration," in Proc. Seventh European Conf. Controlled Fusion and Plasma Physics, Lausanne, 1975 (CRPP, 1975) Vol. I, p. 55 .

9. Dah Yu Cheng, Nucl. Fuston 10, 305 (1970).

10. R. W. Moir, Comittee Report: LLL Re--Evaluation of the Simple Mirror for a Fusion Reactor, Lawrence Livermore Laboratory Rept. UCID-16736 (1975).

11. J. G. Cordey and C. J. H. Watson, "Plasma Diffusion in Toroldally Linked Mirror Ssytems," in Proc. Fifth Conf. Plasma Physics and Controlled Nuclear Fusion Research, Tokyo, 1974 (IAEA, 1975) Vo1. II, p. 643.

12. L. S. Hall and B. McNamara, Bull. Am. Phys. Soc. 19, 872 (1974).

13. W. Heckrotte, et a1., Parametric Survey for the Linear Two Component 3ystem, Lawrence Livermore Laboratory Rept. UCRL-75953 (1974). Breakeven occurs for $T_{e}=T_{1}=4 \mathrm{keV}$ (Fig. 9).

14. A. J. Litchenberg, M. A. Lieberman, and B. G. Logan, Multiple-Mirror Plasma Confinement, U. C. Berkeley Electronics Research Laboratory Memorandum ERL-M541 (1975). 
15. H. P. Furth, Nucl. Fusion 1962 Supp1. Part 1, 169 (1962).

16. J. P. Holdren, Nuc1. Fusion 12, 267 (1972).

17. D. J. Rose, Phys, Flulds 12, 267 (1972).

18. B. Kadomptsev, Reviews of Plasma Physics Vo1 2 (Consultants Bureau, NY, 1966) p. 165.

19. B. Suydam, Finice Larmor Orbit Stabilization, Los Alamos Scientific Laboratory Rept. LA-3260-MS (1965).

20. T. H. Batzer, et al., Conceptual Design of a Mirror Reactor for a Fusion Englneerling Research Facility (FERF), Lawrence LIvermore taboratory Rept. UCRL-51617 (1974).

21. R. C. Davidson and J. M. Ogden, Phys. Fluids 18, 1045 (1975).

22. Lawrence Livermore Laboratory Form 189 No. 29-FY78 (Draft: January 26, 1976).

23. S. Humphries, J. App1. Phys. 46, 137 (1975).

24. D. S. Prono, et al., J. Appl. Phys. 46, 3310 (1975).

25. P. M11ler, et al., in Proc. First International Toplcal Conf. Electron Beam Technology, Albuquerque, 1975 (Sandia Albuquerque Laboratories, in preparation).

26. D. 5. Prono, et al., "Intense, Pulsed, Ion-Dfode Sources and their Application to Mirror Machines," in Proc. First International Topical Conf. Electron Beam Technology, Albuquerque, 1975 (Sandia Albuquerque Laboratories, in preparation).

27. Lawrence Livermore Laboratory Form 189 No. 4-FY77 (May 1, 1975).

28. J. G. Cordey and C. J. H. Watson, in Proc. IAEA Workshop, Culham, 1974 (IAEA, 1974).

29. T. K. Fowler, Lawrence LIvermore Laboratory, unpublished Internal memorandum (May 21, 1975).

30. J. M. Dawson, et al., Phys, Rev. Lett. 26, 1156 (1971). 